\title{
Dynamic Interplay between Modes of Regulation During Motivationally Challenging Episodes in Collaboration
}

\author{
Aishah Bakhtiara, Allyson F. Hadwin ${ }^{\mathrm{a}}$ \\ ${ }^{a}$ University of Victoria, Canada \\ Article received 19 August 2019 / Article revised 12 December / Accepted 21 February 2020 / Available online 24 March
}

\begin{abstract}
The cognitive and social demands of collaboration can raise significant motivation challenges. Task progression relies on team members strategically taking control of the problems and adapting accordingly. Theory indicates that productive collaboration involves groups using three modes of regulation: self-regulation, co-regulation, and socially shared regulation. Despite research demonstrating the occurrence of all three modes in collaboration, it is unclear how these modes interact and how co-regulation supports the emergence of self- and shared-regulation of motivation. The study aimed to examine the role co-regulation played in dynamically stimulating the emergence of self-and shared-regulation of motivation. A cross-case comparison was conducted between two groups who experienced high levels of motivation challenges but achieved contrasting perceptions of the overall team learning productivity. During analysis, groups' dynamic regulatory processes within the online environment were visually represented using a tool called the Chronologicallyordered Representation for Tool-Related Activity (CORDTRA). Findings demonstrate that coregulation of motivation may afford and thwart the emergence of self-and shared-regulation, and these processes interacted with the group's situational challenges and the regulatory skills group members possessed. Comparisons between the two groups indicated that groups' motivation regulation should (a) match the demands of the challenges at hand, (b) be positively supported by group members through co-regulation, and (b) involve a more varied strategic responses so that the group may continue to learn and co-construct knowledge effectively as a team.
\end{abstract}

Keywords: motivation; self-regulated learning; co-regulation; socially shared regulation; CORDTRA diagram 


\section{Introduction}

In recent years, there has been a surge of research examining students' collaboration in physical classrooms and online learning environments (Puntambekar, Erkens, \& Hmelo-Silver, 2011; Järvelä \& Hadwin, 2013). Research on collaborative learning (a) investigates how group members co-construct and build upon each other's knowledge and ideas and (b) examines groups' and individual members' regulation of cognition, behaviour, motivation, and emotions in the learning task (Järvelä \& Hadwin, 2013). The focal point of the second line of research is the dynamic interaction between individual and group regulation. Hadwin, Järvelä, and Miller $(2011,2018)$ posited that regulation in collaboration involves three modes: selfregulation, socially shared regulation, and co-regulation. Self-regulation refers to individual learners' processes of regulating their own cognition, behaviour, motivation, and emotions for personal goals or in the service of the group goal. Socially shared regulation (referred to as shared regulation hereafter) involves the group jointly regulating their cognitive, behavioural, motivational, and emotional states toward a shared outcome. In line with the sociocultural lens of Hadwin, Järvelä, et al.'s (2018) work, the emergence of selfand shared-regulation are temporarily supported or thwarted through co-regulation (Hadwin, Järvelä, et al., 2018). This process involves the reciprocal interaction between the personal, social, and cultural elements, which may facilitate or frustrate the internalization of regulatory skills or information at the individual and group level (McCaslin \& Vriesema, 2018). Thus, co-regulation is more than just capable individuals directing or supporting the learning of less capable individuals. It can be initiated by a single individual, multiple individuals, tools, or the physical task, and it can be directed toward either individuals or the group. However, in many studies, co-regulation is often limited to prompts and guides directed toward individual learners (e.g., DiDonato, 2013; Järvelä, Malmberg, \& Koiveneimi, 2016; Panadero \& Järvelä, 2015). Limited research investigates co-regulation as a process that benefits or undermines either self- or sharedregulation. In response to this shortcoming, Hadwin, Järvelä, et al. (2018) revised their definition and conceptualization of co-regulation form the original (Hadwin et al., 2011) depiction to emphasize the importance of those prompts being taken up by individuals or groups in co-regulatory episodes. Addressing this scarcity requires an in-depth and in-context investigation of the intertwined individual and group processes.

Most research on collaboration concerns cognitive regulation and cognitive outcomes. Rogat, Linnenbrink, \& DiDonato (2013) conclude that motivation regulation and motivational outcomes have been largely ignored in the collaborative learning literature. Even when designing computer support for collaborative learning, the motivational aspect of collaboration is often neglected (Belland, Kim, \& Hannafin, 2013). Research, however, shows that motivation is instrumental in directing and stimulating cognitive processes which are needed when learners work on joint tasks (Rogat et al., 2013). Research demonstrates that shared regulation of motivation affords opportunities for the groups to engage in other forms of regulation, particularly those that involve regulating differences in perspectives and understanding related to the cognitive aspect of the task (Järvelä, Malmberg, \& Koivuneimi, 2016; Malmberg, Järvelä, Järvenoja, \& Panadero, 2015). Nonetheless, working in small groups can raise significant motivation challenges. Inadequate responses to these challenges can lower learners' motivation to engage in future collaboration (Ruiz Ulloa \& Adams, 2004). This negative consequence counters the very aim of collaborative learning which is to promote high engagement with the learning materials (Blumenfeld, Kempler, \& Krajcik, 2006). Motivation challenges have been frequently reported to be a barrier to collaborating with others (Järvenoja, Volet, \& Järvelä, 2013). These challenges may originate from multiple sources including variations in individual members' motivation and attitude toward the collaborative task (e.g., Wosnitza \& Volet, 2014), interpersonal dynamics related to work ethics and personalities (e.g., Tucker \& Abbasi, 2016), and difficulties in negotiating multiple perspectives, ideas, and goals related to the task (e.g., Barron, 2003). Although motivation challenges are common, it is unclear how multiple individuals with diverse motivational beliefs and goals negotiate their motivation for the group task. It has been proposed that motivation is fostered, influenced, and maintained through an ongoing process of co- 
regulation (McCaslin \& Hickey, 2001). Hence, this study aimed to investigate the role co-regulation plays in stimulating self- and shared regulation of motivation in collaboration.

\subsection{Co-Occurrence of Self, Co, and Shared-Regulation}

Research indicates that self-, co-, and shared-regulation co-emerge and mutually reinforce one another. Panadero, Kirschner, Järvelä, Malmberg, and Järvenoja (2015) demonstrated the link between individual members' self-regulation skills and the groups' ability to socially share their regulation of learning, motivation, and emotions. Based on self-report data about individual and group regulation, Panadero et al. found that groups composed of individuals with greater self-regulation skills in managing their cognition, motivation, and emotion were more likely to demonstrate better shared-regulation during collaboration. Similarly, Bakhtiar, Webster, \& Hadwin (2018) found that a group who was more successful in adapting as a team had individuals who (a) were more punctual with their individual assignments and (b) had a better understanding of the task instructions. In Pino-Pasternak, Whitebread, and Neale's (2018) study with pre-schoolers, group members possessing higher global self-regulation skills were found to actively co-regulate their peers and consequently increase team productivity. Overall, research suggests that for shared processes to occur efficiently, individual members must actively self-regulate and support the regulation of others in the service of the group goal.

Group dynamics and processes have also been shown to play a role in promoting and shaping groups' shared regulation of motivation. By analyzing groups' interaction, dialogue, and behaviour, research demonstrates that positive socioemotional interaction is associated with instances of high-quality and more adaptive shared regulation (Isohätälä, Jävenoja, \& Järvelä, 2017; Rogat \& Linnenbrink-Garcia, 2011). Positive socioemotional interaction has been operationalized as involving group members being attentive to one another, acknowledging others' contributions, and respectfully soliciting opinions. Research also demonstrates that co-regulation when performed in a directive, rather than facilitative, manner can negatively influence the group dynamics and shared processes (Rogat \& Adam-Wiggins, 2015). Rogat and Adam-Wiggins characterized directive co-regulation as involving the co-regulator asking individuals to comply with specific ideas and approaches without much consideration of the other person's point of view. In contrast, facilitative co-regulation considers the well-being and motivation of team members and is often pro-actively activated to avoid experiencing challenges that might disrupt progress. These studies highlight the importance of positive reciprocal contributions and participations among group members when regulating as a team.

A review on shared regulation indicates that the phenomenon has often been characterized through qualitative data on groups' conversations during collaboration (Panadero \& Järvelä, 2015). The authors point out a trend suggesting that collaboration with higher instances of co-regulation characterized by one individual taking the lead has been less optimal for performance than collaboration with higher instances of shared regulation. Note, however, only a few of the studies reviewed by Panadero and Järvelä (2015) provided evidence for the link between performance and shared regulation. Moreover, shared regulation in those studies tended to focus on regulation that is more cognitive-focused rather than motivational or emotional-focused. As observed by the same authors, the theoretical distinctions between co-regulation and shared regulation are rarely made in the studies they reviewed (see also Hadwin et al., 2011). Since the review, research evidences mixed findings about the frequency effect of co- and shared-regulation on group performance. For example, Schoor and Bannert (2012) reported no difference in the amount of shared regulation between high- and low-performing dyads. Regardless of these findings, we argue that the frequency of "sharedness" is less important than activating appropriate regulation modes to fit the situational demands and challenges. This argument is particularly relevant in motivation regulation because research indicates that self-regulating one's motivation and co-regulating group members' motivation alone can be sufficient without needing shared-regulation to frequently occur (Järvenoja, Järvelä, \& Malmberg, 2017). In Järvenoja et al.'s study, co-regulation of motivation involved one or several group members trying to "increase motivation within the group or offered support, advice or encouragement when group members 
expressed a lack of motivation or negative feelings affecting the group work" (p. 6). For instance, when an individual experienced a lack of interest, having another group member suggest making the task personally relevant was enough to increase the individual's motivation. Fundamentally, self-, co-, and shared regulation are activated based on the needs and the types of challenges the situation presents (Hadwin, Järvelä, et al., 2018).

\subsection{Regulating During Motivationally Challenging Situations}

Hadwin, Järvelä, et al.’s $(2011,2018)$ conceptualized self-, co-, and shared-regulation as being driven by the same cognitive architecture described in Winne and Hadwin (1998). This cognitive architecture is represented by the acronym COPES (conditions, operations, products, evaluations, and standards) which describes several interacting elements during a process of regulation. The COPEStypology highlights the need for viewing regulation as triggered by specific contextual demands or challenges that stall goal progress. Specifically, a person's conditions create contexts for regulation. In collaboration, conditions can exist in three areas: (a) self, (b) group, and (c) task and context (Hadwin, Järvelä, et al., 2018). Self-conditions include personal characteristics, beliefs, and histories individuals bring to the task. In contrast, group conditions include individual perceptions of their group's shared characteristics, knowledge, norms, and histories. Task and context conditions include individual perceptions about the situation, including affordances and constraints in the task and environmental context. All three conditions dynamically interact and produce complex contexts for regulation.

Conditions are realized through metacognitive monitoring either self-activated or nudged by others or tools. Researchers may introduce metacognitive prompts to encourage students to stop and reflect on their current conditions or challenges and promote students to proactively take control of their situations (e.g., Järvelä et al., 2015; Järvenoja et al., 2017). Evidence suggests that prompts and awareness tools targeting motivation and emotions introduced early in the collaboration can be effective in supporting groups' socioemotional experience which is essential in productive collaborative learning (Järvenoja et al., 2017; Näykki, Isohätälä, Järvelä, Pöysä-Tarhonen, \& Häkkinen, 2017). In theory, when students reflect on their conditions and evaluate them as warranting further interventions, learners may exert control by engaging cognitive operations to process and manipulate relevant information. In terms of motivation regulation, the information is motivation-related (Winne \& Hadwin, 2008; Winne \& Marx, 1989). For example, an individual may search for information about their efficacy belief, boost that belief by assuring they can do the task, and focus on that information to persist in the task (SRL). Likewise, individuals can help others recognize information about their motivation and use it to support others' regulation (CoRL). When regulating as a team, group members may articulate personal concerns regarding the group's overall engagement and negotiate to work toward one common goal. The results of operations create products that can manifest cognitively (e.g., increased understanding of task goal and value), behaviourally (e.g., persistence in the task), and emotionally (e.g., in the state of flow) during the task. Learners then construct judgments or evaluations of the products by comparing them to specified or perceived standards or goals.

Research demonstrates that groups' regulatory processes are different under varying levels of challenges (Sobocinski, Malmberg, \& Järvelä, 2017). Sobocinski et al. examined the temporality of the regulatory phases (forethought, performance, and reflection) in high and low challenge events across eleven collaborative groups. High and low levels of challenges were determined based on groups' aggregated responses related to their cognitive, motivational, and emotional states collected at the beginning of each collaborative session. The observed moment-by-moment regulatory actions in each challenge level were then fed into a process mining software to detect the most common sequence of actions. Findings showed that the frequency of regulatory processes was similar in high and low challenge level events. However, the sequential pathways of the processes slightly differed: during a high level of challenge, groups switched between forethought and performance more often. Although there was little information on the types of difficulties the groups experienced and the intended purpose of engaging in the frequent switch, Sobocinski 
et al.'s findings suggest that more intense challenges require learners to adapt and refine their approaches more frequently.

Experiencing more challenges, however, does not necessarily equate to performing poorly in the task. Groups who experienced similarly high levels of challenges may end up with different outcomes as each group's situational affordances and constraints may vary (Järvenoja, Järvelä, \& Malmberg, 2015). Researchers argue that successful regulated learners are identified by their ability to overcome situationspecific challenges; these individuals often exhibit more accurate metacognitive awareness of their situations and possess a more varied strategy repertoire (Hadwin \& Winne, 2012). Responses that are not fitting with the task demands or the challenges present in the task would theoretically be less effective than responses that directly address the situational needs and challenges (Hadwin \& Winne, 2012). Examining what many learners do in response to highly challenging situations may bring to light critical features of strategic actions that may be more adaptive for learning.

Motivation challenges in collaboration emerge from a variety of individual and situational sources (Rogat et al., 2013; Järvelä, Järvenoja, \& Veermans, 2008). Bakhtiar, Hadwin, and Järvenoja (2018) argued that there are several types of motivation challenges. The challenges can be categorized into (a) behaviourbased - difficulties related to effort initiation and maintenance; (b) cognitive-based - difficulties related to cognitive beliefs about one's competence, task value, and goals; (c) affective-based - difficulties related to task enjoyment; and (d) externally-based - difficulties related to environmental distractors pulling away one's attention from the task. These challenges can lower individuals' and the group's motivation to engage in a collaborative task.

Bakhtiar, Hadwin, et al. (2018) found that group members tended to resort to behaviour control strategies to address difficulties related to group members' effort initiation and participation in the task. These strategies were in the form of providing social support, focusing on task completion, and checking each other's progress. Behaviour control strategies were more dominant regardless of the data indicating that cognitive control strategies, such as planning and setting or revising goals, to be better at reducing the likelihood of encountering the same type of motivation challenge again. The authors' analyses were based on data about individual members' perceptions of their strategy use. It is still unclear how motivation regulation strategies are performed under co- or shared-regulation modes. This current study addressed this gap by exploring motivation regulation strategies learners deployed individually (SRL), for others (CoRL), and collectively as a team (SSRL).

\subsection{How Can the Dynamic Interplay Between Modes of Regulation be Captured?}

Investigating how individual team members dynamically negotiate their motivation for the group task involves examining the specific actions that unfold during groups' episodes of motivation regulation (Järvenoja et al., 2018). Such an undertaking often requires researchers to intricately code group members' utterances across multiple dimensions of regulation to make sense of the multi-layered processes (see Volet \& Vauras, 2013). These dimensions can include micro-processes (planning, monitoring, adapting), targets (behaviour, cognition, motivation), and modes of regulation (see Bakhtiar, Webster, et al., 2018; Rogat \& Linnenbrink-Garcia, 2011). However, code frequencies are typically examined according to one dimension at a time, which undermines the dynamic interactions between the coded processes. Our aim to examine the dynamic interplay between modes of regulation during motivationally challenging episodes implicates finding a method that can holistically capture (visually) the complex processes. The use of each mode of regulation must also be contextualized by including information about (a) the individuals involved in the regulation, and (b) the specific motivation regulation strategy enacted within the episode.

Thus far, previous studies have explored three approaches for capturing groups' regulatory processes using (a) process mining tools (e.g., Malmberg et al., 2015), (b) social network analysis (e.g., Wijga, Endedijk \& Veldkamp, 2019), and (c) probabilistic decision pathways (Hadwin, Bakhtiar, \& Miller, 2018). In these approaches, groups' regulatory activities are visually represented to aid the analysis of 
related events: process miners generate common sequences of regulatory events, social network analyzers produce a network of relationships between group members' regulatory activities, and probabilistic pathways are represented using directed graphs to map learners' transition from one event to another. One limitation of using these approaches lies in their inability to holistically capture the activities involved in multiple episodes of regulation. At best, the visualization focuses on either the dynamic person-to-person relationships (person-focused) or the frequently traversed sequence of actions (activity-focused) aggregated across episodes of regulation.

In this study, we explored a method for visually representing the dynamic interplay between individual and group motivation regulation called the Chronologically-ordered Representation for ToolRelated Activity (CORDTRA) diagram (see Hmelo-Silver, Chernobilsky, \& Jordan, 2008). The CORDTRA was initially designed to capture group members' interactions with support tools in a computer-supported collaborative learning environment. For instance, a diagram may show that, within a defined time block, specific individuals are viewing a discussion board while also generating ideas aloud. The CORDTRA diagram is adaptable to data about group regulation because the diagram can visually represent fine-grained and multi-dimensional codes associated with regulation. Specifically, the diagram is a scatterplot time-series of coded data that can represent individual members and specific regulatory actions. Arranging each group member's activities chronologically allows researchers to unpack how individual and group regulation evolve during the collaboration. CORDTRA diagrams provide opportunities to examine the larger patterns that emerge between codes and foster holistic visualization of the dynamic processes. During pattern identification, researchers may cycle back and forth between the diagram and the actual conversation data for further context on the specific utterances involved during those activities.

\subsection{Purpose}

The purpose of this study was to examine the role co-regulation of motivation plays in dynamically stimulating the emergence of self- and shared-regulation of motivation in two groups with contrasting perceptions of their overall team learning productivity. A cross-case analysis was conducted between two groups who experienced similarly high-level motivation challenges but demonstrated contrasting outcomes in terms of their team learning behaviour or effectiveness in co-constructing ideas and knowledge during collaboration. Groups were compared based on three guiding research questions:

i. What motivation challenges trigged regulation?

ii. How were self- and shared-regulation used in relation to co-regulation?

iii. What strategies were used during episodes of motivation regulation?

\section{Methods}

\subsection{Case Study}

A case study method was chosen for conducting the cross-case comparisons for three reasons. First, the dynamic interplay between groups' self-, co-, and shared regulation in response to motivation challenges is a complex social phenomenon, and it is not clear how the dynamic process occurs during learning. Case studies have been argued to be appropriate for answering the how questions (Yin, 2003). Second, case studies involve in-depth and in-context empirical investigations in which there is no manipulation of behaviour. Instead of examining the effect of a specific manipulation, case studies involve using multiple data sources to understand the phenomenon in question. The collaborative interaction examined in this study was not manipulated as we were interested in investigating learners' responses to naturally occurring motivationally challenging events. Third, while case studies are not meant for generalization to populations, findings are generalizable to theoretical propositions (Yin, 2003). In this study, we tested (and consequently 
informed) the theory relating to self-, co-, and shared regulation as proposed in Hadwin, Järvelä, et al. (2018).

\subsection{The Collaborative Project}

Participants were enrolled in an undergraduate elective Educational Psychology course on learning strategies and academic success. Students in the course came from a wide range of disciplines and levels of academic achievements. In the course, students were required to complete a graded semester-long collaborative project in groups of three to five. The project required groups to produce and present a strategy for tackling one aspect of university learning in the form of an infographic. Students approached the project in eight work sessions distributed across the semester: individual planning task, group planning task, three online discussion sessions, building the infographic, presenting the final infographic, and individual reflection task. Within each work session, cognitive and metacognitive prompts were introduced to promote productive collaborative learning. These prompts were also used as a data collection tool focusing on attaining students' metacognitive reflections and decisions regarding their motivation in the collaboration. Cumulatively, the project was worth $35 \%$ of the course mark. Details of the work sessions are described below.

\subsubsection{Individual Planning Task}

This activity was designed to guide students through a process of systematically unpacking information about the project and using that understanding to strategically plan for the task. Specifically, individual students (a) summarized their understanding of the collaborative project, (b) evaluated examples of past students' infographics, (c) reflected on their goals and motivation for the task, and (d) constructed a plan for tackling the main motivation challenge they anticipated experiencing in the collaboration. Students were given 15 minutes to complete this task during class.

Group assignment using individual planning scores. The individual planning task was worth 5\% of the course mark. An excellent planning showed that the student leveraged the task to get ready for the project and provided thoughtful answers. Short cryptic answers indicated poor planning. Planners were graded by two course instructors who cross-checked their marking for inconsistencies. Students within course sections were assigned to groups based on their planning scores. Specifically, students were distributed to include group members with high (5\%), moderate (3-4\%), and low (1-2\%) planning scores. This distribution was so that all groups had similar variability in terms of how well prepared its members were.

\subsubsection{Group Planning Task}

Group members met in person during group planning. Guided by eight open-ended prompts, groups were tasked to plan their approaches and interactions for the project. An example of a prompt included: What is our strategy for preparing for each part of the project? Groups were given 20 minutes of class time to plan and were encouraged to record their meeting minutes. Group planning was not graded. Consequently, the meeting minutes were shallow, making them unusable for data analysis.

\subsubsection{Online Discussions (3 sessions)}

In the next three sessions, groups collaboratively discussed and documented their ideas related to their group's infographic using shared online documents, Google Docs. Each session had a different topic focus assigned by the instructors, but the topic builds upon one another to help students gradually build their group's final infographic. Each session was worth 5\% of the project mark. In all three sessions, groups were required to use an online text-based chat tool (Google Hangouts) to interact and discuss their ideas. Essentially, during each session, each student had two online applications opened on their individual computer: (a) Google Hangouts for communicating with group members and (b) Google Docs for recording ideas and resources collaboratively (Figure 1). Groups were given 60 minutes of class time to work on each 
topic. Incomplete work was assigned to be completed outside of class time using the same Google tools. Groups were given a week to submit work from each session.

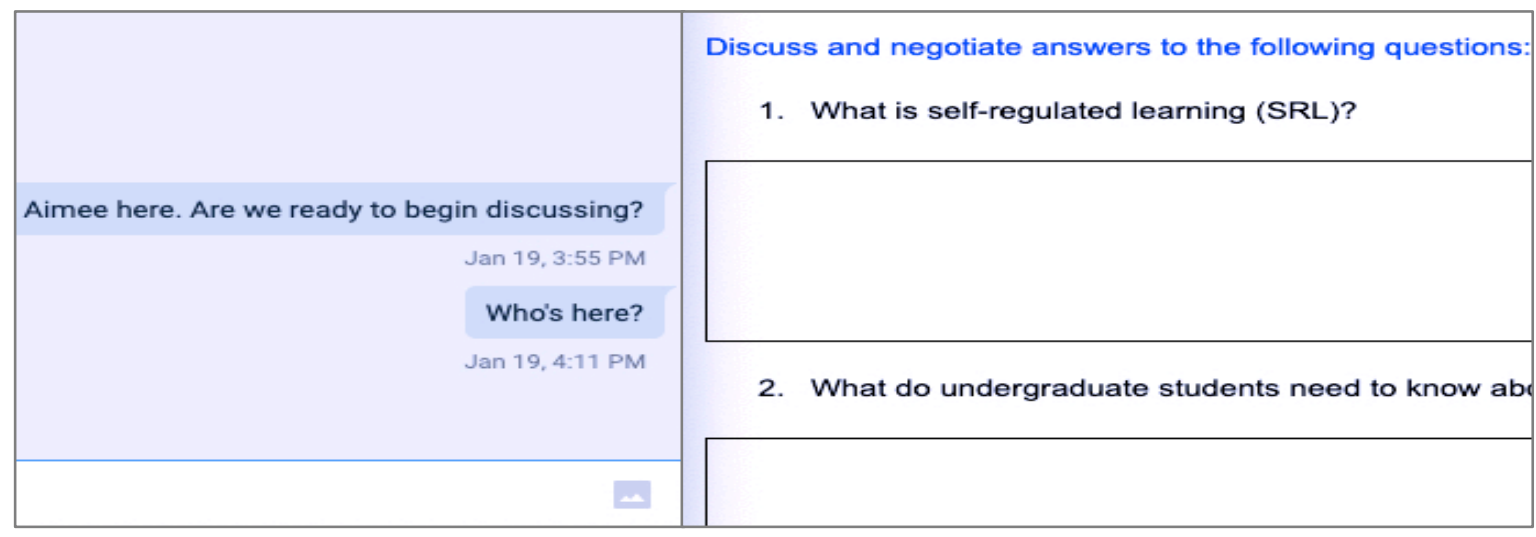

Figure 1. Example of a group's online work session. Google Hangouts environment (left) and Google Docs environment (right).

\subsubsection{Building the Infographic}

Groups built an infographic face-to-face during class time. In this phase, groups turned their resources and ideas (collected in the previous online discussion sessions) into an infographic format. The infographic was produced within the online environment using available templates in Google Slides. Group members were able to concurrently access, edit, and track changes to their infographic.

\subsubsection{Presenting the Infographic}

In the final week, groups presented their finished infographic to other students in their course section. The final infographic and the accompanying group presentation were worth $10 \%$ of the project mark.

\subsubsection{Individual Reflection Task}

At the end of the project, students reflected on the overall collaborative experience which included (a) assessment of their team learning behaviour and the final product, (b) reflection on experienced challenges, and (d) a plan for improving their future collaborations. This portion of the assignment was worth $5 \%$ of the project mark. Students were graded on the overall thoughtfulness of their reflection.

\subsection{Data Sources}

Figure 2 provides an overview of the collaborative project and the data sources gathered for this study. Descriptions of each data source follow.

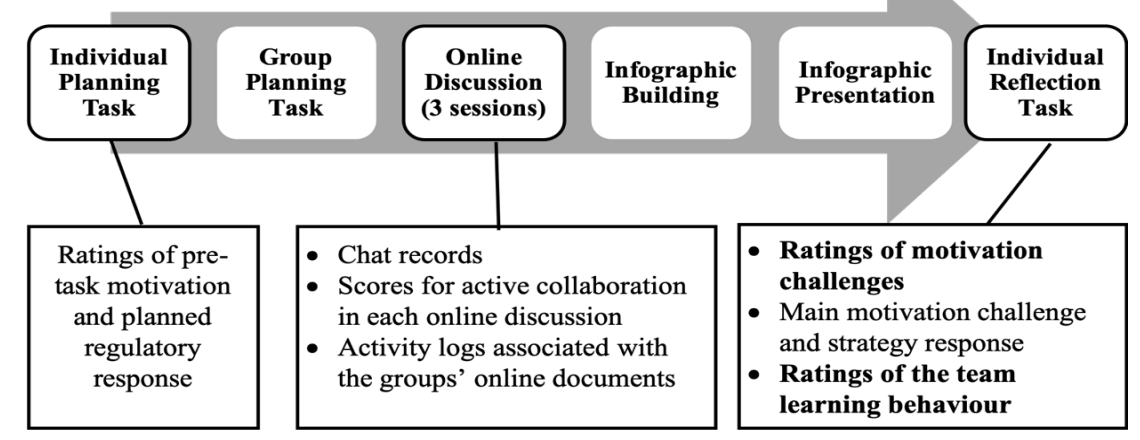


Figure 2. Overview of the work sessions in the collaboration project (above) and the data sources gathered for this study (below). Bolded data sources were used for the case sampling strategy.

\subsubsection{Individual Pre-task Motivation and Planned Response}

During individual planning, students completed a narrative constructor tool to reflect on their motivation for the task (Figure 3). For each prompt, students select a response option from a drop-down menu. The tool asked individuals to (a) rate their task motivation, (b) provide a reason for that rating, (c) evaluate whether that motivation was a problem, (d) provide a goal for regulation, and (e) describe a strategy response. If the strategy was not one of the options, students had to specify their planned strategy in a text field.

\begin{tabular}{|c|c|c|c|c|c|c|c|}
\hline \multicolumn{7}{|c|}{ it sounds like a lot of work (b) } & \multirow{3}{*}{$\begin{array}{l}=\text { this } \\
\Rightarrow \text {. If }\end{array}$} \\
\hline \multirow{2}{*}{$\begin{array}{l}\text { motivation is } \\
\text { motivation by } \\
\text { other, please }\end{array}$} & \multicolumn{2}{|l|}{ very (c) } & \multicolumn{2}{|c|}{ problematic, and I would like to } & increase & & \\
\hline & \multicolumn{6}{|c|}{$\begin{array}{l}\text { focusing on the things I could successfully complete (e) } \\
\text { pecify: }\end{array}$} & \\
\hline \multicolumn{5}{|l|}{ (f) } & & & \\
\hline \multicolumn{4}{|l|}{ Section } & \multicolumn{4}{|c|}{ Response options for each section } \\
\hline \multicolumn{4}{|c|}{ (a) Individual pre-task motivation } & \multicolumn{4}{|c|}{ Not at all, Slightly, Moderately, Very, or Extremely } \\
\hline \multicolumn{4}{|c|}{ (b) A justification for that motivation } & \multicolumn{4}{|l|}{ Open-ended text field } \\
\hline \multicolumn{4}{|c|}{ (c) Evaluation of the consequence to learning } & \multicolumn{4}{|c|}{ Not at all, Slightly, Moderately, Very, or Extremely } \\
\hline \multicolumn{4}{|c|}{ (d) Regulation goal } & \multicolumn{4}{|c|}{ Increase, Decrease, Maintain, or Do nothing } \\
\hline \multicolumn{4}{|c|}{ (e) Strategy response } & \multicolumn{4}{|c|}{$\begin{array}{l}\text { Demonstrating to others how to work on the task, Ignoring the } \\
\text { problem, Promising a reward for completing the task, Focusing } \\
\text { on something I could successfully complete, Reminding myself } \\
\text { of the goals and priorities, Taking control of emotions that were } \\
\text { harmful for productivity, Focusing on making the task } \\
\text { interesting, Revising my plan, Doing a better job monitoring my } \\
\text { conditions and progress, Giving my bear minimum, or Other. }\end{array}$} \\
\hline \multicolumn{4}{|c|}{ (f) Description of "Other" strategy } & Open-ended text field & & & \\
\hline
\end{tabular}

Figure 3. A narrative constructor tool for collecting data about individual pre-task motivation and planned strategic response.

\subsubsection{Chat Records}

Groups' text-based conversations during the three online discussion sessions served as the primary data source because they provided evidence of groups' self-, co-, and shared-regulation. For each text-based utterance, Google Hangouts provided a timestamp, date, and the username belonging to the utterance.

\subsubsection{Scores for Active Collaboration in Each Online Discussion}

For each online discussion session, the course instructors rated each group's quality of collaborative conversations. Groups received a score representing their teamwork quality including team members' attempts at actively co-constructing ideas and knowledge as a group. Groups received a full mark (2 out of 2 ) if every member in the team actively contributed in meaningful ways. A half mark ( 1 out of 2 ) was given if there was evidence that group members were trying to contribute in some ways but lacked active coconstruction of ideas and knowledge. Groups received a score of zero if they did not meet online to complete the assigned work.

\subsubsection{Activity Logs Associated with The Shared Online Documents}


Students' activity logs within each Google Document were automatically collected in the online environment. Each log contained information about (a) who viewed or edited a document, (b) the document name, and (c) when the activity was performed. For each group member, the percentage of editing work the person completed relative to their group in each shared document was calculated. For example, when a person edited the group's document 5 times out of the group's total of 50 times, the person's percent editing work for that work session would be $10 \%$. This calculation was used to gauge each member's contribution to each discussion session

\subsubsection{Ratings of Experienced Motivation Challenges}

At the end of the project, each member rated the extent to which they experienced several types of motivation challenges during collaboration. Three items were used to collect ratings about motivation challenges including (a) difficulties in getting individuals to participate, getting the work done, and staying on task (behaviour-based); (b) difficulties with cognitive beliefs about one's competence, task value, and goals (cognitive-based) and (c) difficulties in maintaining positive attitudes and emotions about the task, the group, and the situation (affective-based). Ratings were collected on a five-point Likert scale from $1=$ not a problem to $5=$ major problem. For each student, ratings on all three items were summed to produce an individual score of experienced motivation challenges. At the group level, group members' scores were averaged to produce the group's mean ratings of experienced motivation challenges. Within-group agreement regarding the challenges was denoted using the standard deviation of the group's mean score.

\subsubsection{Main Motivation Challenge and Its Regulation}

Students were subsequently asked to reflect on one main motivation challenge their group encountered during the collaboration (Figure 4). This reflection required students to construct a narrative about (a) the main motivation challenge the group experienced, (b) the strategy used to address the challenge, (c) why the strategy was selected, (d) the strategy effectiveness, and (e) who was involved in enacting the strategy.

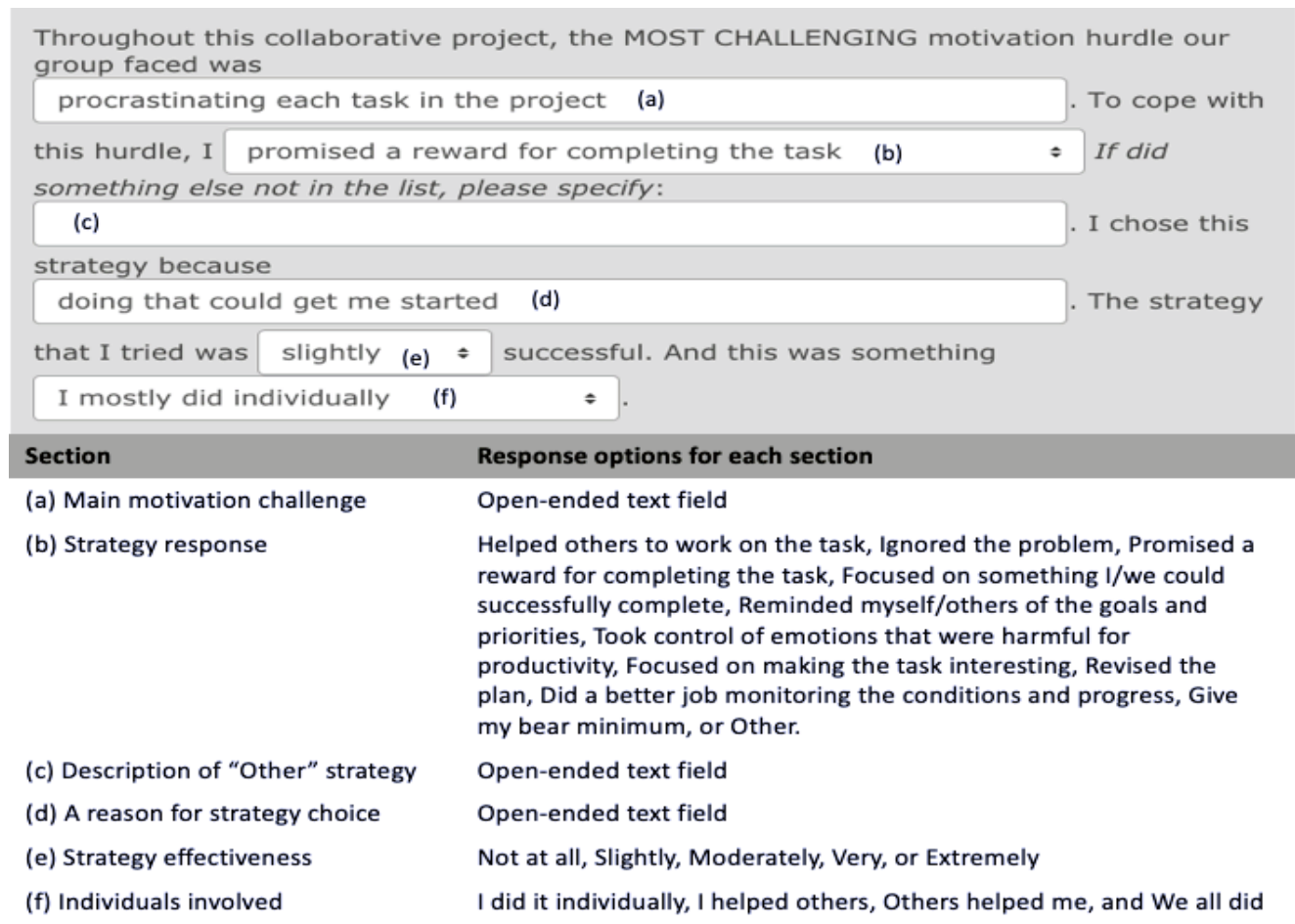

Figure 4. A narrative constructor tool for collecting data about the main motivation challenge and strategy response. 


\subsubsection{Ratings of The Team Learning Behaviour}

In the reflection phase, group members also evaluated their team learning behaviour using a nineitem Team Learning Behaviour questionnaire adopted from Van den Bossche, Gijselaers, Segers, and Kirschner (2006). Scores on the questionnaire describe the degree to which group members construct, coconstruct, and build upon each other's ideas and contributions. Higher ratings indicate a more positive team learning behaviour demonstrated during collaboration. An example of an item on the questionnaire included, "My team members elaborated on each other's information and ideas." All responses were collected on a seven-point Likert scale ranging from $1=$ strongly disagree to $7=$ strongly agree .

\subsection{Case Sampling Strategy}

Two groups were sampled from a pool of 20 groups using two criteria. (1) Informed by research that indicates challenging events as opportunities to exercise regulation, both groups must have experienced similarly high levels of motivation challenges thereby having had similar opportunities to regulate motivation. (2) The two groups must have maximally different perceptions of the overall team learning productivity (i.e., team learning behaviour ratings). This latter criterion was chosen to identify the types of regulatory actions that were more successful and less successful in influencing team motivation and productivity. Accordingly, groups were selected based on data collected at the end of the collaborative project related to group members' post-collaboration judgment of (a) the level of motivation challenge experienced during collaboration and (b) the overall team learning behaviour their group demonstrated.

The sample was identified in stages. First, groups with missing data from at least one member were removed, leaving 12 cases remaining. Next, groups' ratings of motivation challenges were categorized as: (a) high, including scores falling above $0.5 \mathrm{SD}$ from the mean $(n=5)$, (b) medium, including scores between -0.5 to $0.5 \mathrm{SD}$ around the mean $(n=1)$, and (c) low, including scores falling below $0.5 \mathrm{SD}$ from the mean $(n=6)$. Demarcations of the standard deviations were based on the average group ratings of motivation challenges across all groups in the sample $(M=6.15, S D=1.71)$. Next, to obtain the richest regulation data, we retained groups in the high challenge category $(n=5)$ assuming these groups had the most opportunities to regulate motivation challenges. Finally, from the 5 cases, the group with the highest (Group F) and the group with the lowest (Group K) team learning behaviour score were selected because they represented maximally different group perception of the overall team learning productivity. The difference in team learning behaviour scores between the two selected groups was more than one standard deviation away based on the overall mean ratings of team learning behaviour across all groups $(M=56.21 ; S D=6.27)$. Hereafter, the group with a more positive perception of their overall team learning productivity was referred to as the high productivity group, and the group with a less positive perception of their overall team learning productivity was referred to as the low productivity group. Table 1 summarizes the characteristics of the case groups.

Table 1

Characteristics of Each Case Group

\begin{tabular}{lcc}
\hline & $\begin{array}{c}\text { High Productivity } \\
\text { (Group F) }\end{array}$ & $\begin{array}{c}\text { Low Productivity } \\
\text { (Group K) }\end{array}$ \\
\hline Group mean (SD) age & $19.75(2.06)$ & $19.40(1.51)$ \\
Number of males & 2 & 3 \\
$\begin{array}{l}\text { Number of females } \\
\text { Group infographic score out of 10 }\end{array}$ & 2 & 2 \\
$\begin{array}{l}\text { Group mean (SD) ratings of experienced motivation } \\
\text { challenges }\end{array}$ & 7.80 & 7.30 \\
$\begin{array}{l}\text { Group mean (SD) ratings of team learning } \\
\text { behaviour }\end{array}$ & $55.00(5.75)$ & $7.60(2.88)$ \\
\hline
\end{tabular}


Note: Excluding group performance score, parentheses refer to the within-group standard deviation associated with the mean. Productivity was defined as group members' aggregated perceptions of their team's overall ability to build upon on each other's ideas and contributions and work efficiently as a team.

\section{Analysis}

Data analysis was conducted in four steps. This systematic approach was essential for maintaining the chain of evidence and establishing rigour (Seale \& Silverman, 1997).

\subsection{Data gathering}

The first step involved becoming familiarized with the data sources. Elaborative running records of the groups' conversations and activity logs were created by matching the timestamp of the activity logs and the chat conversations, providing a summary of all the events that occurred during each group's online collaboration. Individual members' self-reports were also reviewed and cross-checked with the objective data.

\subsection{Coding of Chat Data.}

Groups' chat records from their online discussion sessions were coded in four waves (see Appendix A and B for coding schemes). The unit of coding was at the episode level. Given the nature of the chat data, a code could be assigned to a single utterance, multiple utterances that may have been separated in between another code, or several consecutive utterances as long as the utterances were still related to one purpose of actions. Codes were mutually exclusive. In each wave, $30 \%$ of the data were given to a second-rater (a senior research assistant) for a reliability check. Inter-rater reliability was determined by Cohen's Kappa statistics. Indices between .80 to .90 were considered strong reliability (McHugh, 2012).

Wave 1: Task-focused versus socioemotional-focused episodes. First, group conversations were segmented into task-focused and socioemotional-focused episodes following Järvenoja et al.'s (2017) coding scheme. Task-focused episodes referred to utterances related to task details, including domain related knowledge or items to include in the group's shared product. Socioemotional-focused episodes referred to utterances about motivation and emotions related to individuals, a group of individuals, task features, progress, or product. In the high productivity group, $39.59 \%$ of the utterances were socioemotional-focused. Comparably, in the low productivity group, $36.38 \%$ of the utterances were socioemotional-focused. Interrater reliability index for coding in this wave was Cohen's $K=.89$.

Wave 2: Types of motivation challenges. The socioemotional conversations were further scrutinized for utterances depicting motivation challenges. $2.15 \%$ of socioemotional utterances in high productivity group and $7.46 \%$ of socioemotional utterances in low productivity group were not considered related to motivational challenges. The eliminated utterances pertain to off-task conversations, where group members shared about personal events (e.g., leaving town to see a family in the weekend) or general remarks about their university courses. Groups' remaining socioemotional utterances were broken down into several episodes of motivation challenges. In other words, the beginning of a challenge episode is marked by utterances that led to the emergence of a motivation challenges or related challenges (e.g., unclear task goals with low engagement), and the end of a challenge episode is marked by utterances that led to a dissolution of a challenge or related challenges. There were instances where a dissolution was not reached; the end of those episodes was marked by group members' shifts in the topic of conversations. Utterances that depict instances of motivation challenges were identified by demonstrated difficulties initiating or engaging in the task, or explicit statements about encountering a motivation hurdle. Motivation challenge utterances were deductively categorized into four types: (a) behavioural-effort initiation and task persistence, (b) 
cognitive - competency beliefs, task value and utility, and goals, (c) affective-interest, enjoyment, positive and negative emotions, and (d) external_-environmental distractors (Bakhtiar, Hadwin, et al., 2018). Interrater reliability index of the motivation challenge coding was Cohen's $K=.83$.

Wave 3: Modes of regulation. Instances of self-, co-, and shared regulation enacted as a response to the motivation challenges were then identified. Coding in this wave was guided by the coding scheme in Bakhtiar, Webster, et al. (2018). Next, instances of self-, co-, and shared-regulation were grouped into a larger motivation regulation episode to identify when the regulatory actions for a challenge began and ended. It was possible to have more than one regulation mode within one motivation regulation episode because a challenge can be addressed using multiple modes at the same time. Inter-rater reliability index was Cohen's $K=.81$.

Wave 4: Motivation regulation strategies. In the last wave, the types of motivation regulation strategies enacted within the regulation episodes were identified. Coding in this wave was guided by Bakhtiar (2019) and Bakhtiar, Hadwin, et al. (2018) coding scheme outlining types of motivation regulation strategies in online collaborative contexts. Inter-rater reliability index was Cohen's $K=.85$.

\subsection{Code Revision and Visualization.}

Next, codes were reviewed, revised as necessary, and visually represented in chronological order on a CORDTRA diagram (e.g., Figure 5). The preparation of the diagram was guided by Hmelo-Silver et al. (2008). However, three modifications were made to the diagram. First, instead of listing code names in the legend, each row represents a code. Second, episode breaks were added to show that the episodes were not necessarily on a continuous timeline. Third, horizontal lines between categories of codes were added for clarity. Each group's processes were visually represented on three levels: (a) person—showing each group member's initiation of and participation in the regulation, (b) mode-showing whether self-, co-, or shared was involved, and (c) strategy - showing the types of motivation regulation strategies applied in the episode.

\subsection{Summarization of Data Across Sources.}

For each group, the frequencies of self-, co-, and shared-regulation instances were summed across episodes. Then, the group's percentage of co-regulation that promoted self- and shared-regulation were summed by inspecting the episodes represented on the group's CORDTRA diagram. Group's conversation data were cross-checked for further context about the regulatory actions demonstrated within each episode. For example, in Episode 4 in Figure 5, Person B can be seen co-regulating Person M by using a social support strategy. The co-regulation promoted Person M's self-regulation who later regulated by expressing his emotions to Person B. Note that Person B's co-regulatory utterances were interleaved by Person M's self-regulatory utterances; however, this is considered one instance of co-regulation and one instance of self-regulation. The dashed lines indicate the beginning of episodes and episode numbers are marked on the top edge of the lines. Codes' sequences on the diagrams were also examined in terms of their chronological information (how early or late a code occurs), in terms of their overlap with other codes, and if a specific sequence of codes frequently occurs in multiple episodes. For instance, in Figure 5, expressing emotions strategy (green diamond) precedes social support strategy (yellow diamonds). There is also a pattern of social support strategy (yellow diamonds) being used during co-regulatory utterances (pink triangles) and commonly activated by Person B (blue circles). At the end of Step 4 of data analysis, each group's data across all sources were synthesized and a cross-data summary for each group was prepared. 


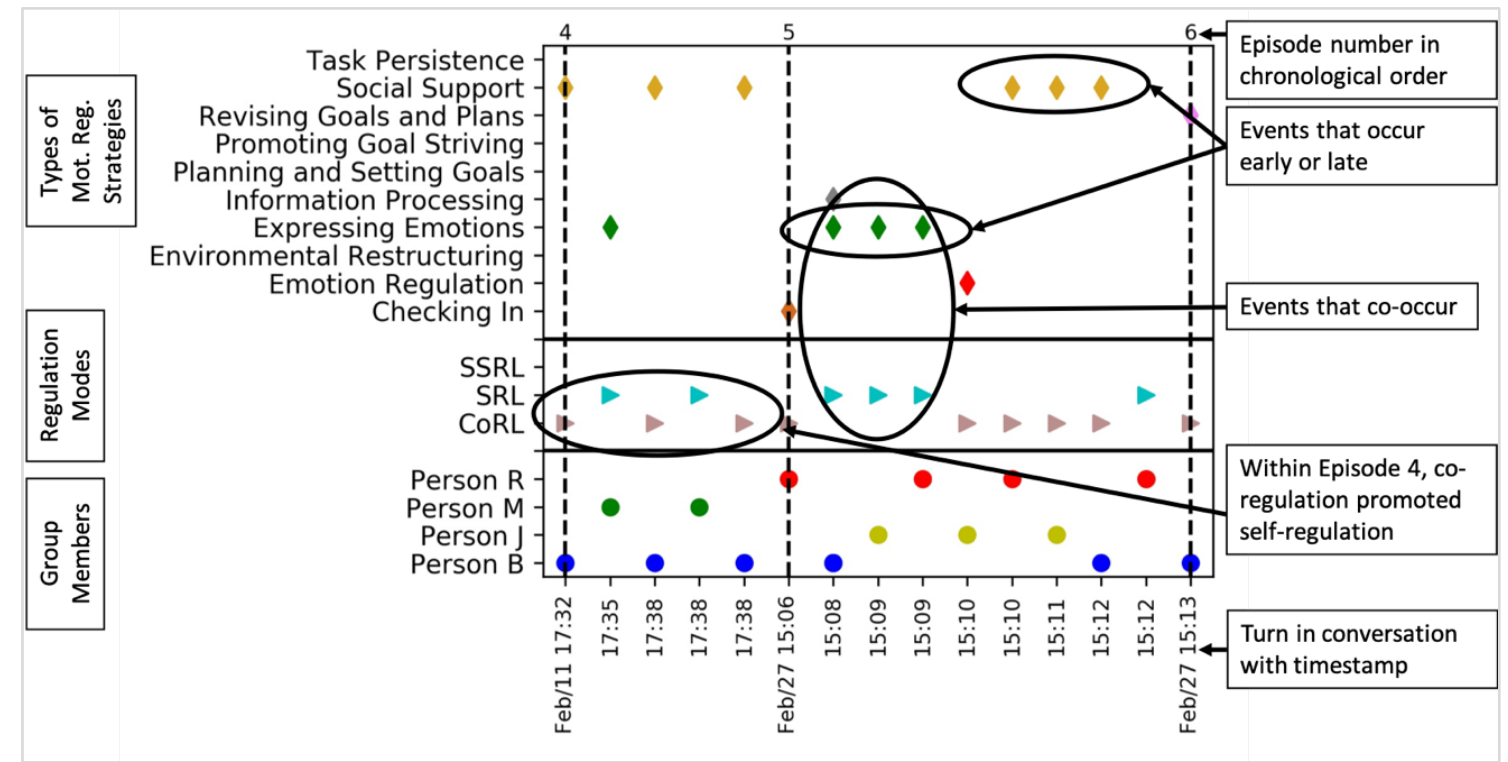

Figure 5. Example of a CORDTRA diagram adapted for this study. The $x$-axis represents the timestamp for each conversation turn. One conversation can have multiple codes. The $y$-axis represents three categories of codes separated by horizontal lines: types of motivation regulation strategies (top), regulation modes (middle), and group members involved (bottom). Each dashed line represents the beginning of an episode, with the corresponding episode number marked above the line.

\subsection{Case Comparisons}

The last step involved a cross-case analysis of the key similarities and differences between the two groups as guided by the research questions. This analysis was recursive involving identifying emerging themes, looking for data reference that either support or contradict the themes, and revising the overall themes.

\section{Findings}

\subsection{What Motivation Challenges Triggered Regulation?}

The regulation of learning model used as a framework for this study (Hadwin, Järvelä, et al., 2018) highlighted the importance of contextualizing students' regulation by examining the conditions that triggered regulatory actions. For this reason, groups' motivational challenges were first examined. Analysis of data revealed two areas of differences: (a) task participation level and (b) motivation challenges triggered by self- versus group conditions.

\subsubsection{Task Participation Level}

In both groups, there were imbalances in terms of each member's percentage of editing work. Some group members contributed to the product notably more than others (Table 2). However, these imbalances were less evident in the high productivity group compared to the low productivity group. Data indicated that all members in the high productivity group were involved in all collaborative sessions. In the second and third sessions, the group actively discussed their ideas and knowledge as evident by the teacher-rated collaboration score. Group members' reflections indicated overall satisfaction with group members' contribution frequency. 
In contrast, the low productivity group started strong; they actively collaborated in the first session and were given a full mark for active collaboration. Unfortunately, some group members' participation dwindled thereafter. Editing work became significantly uneven coupled with one missing member in Session 2 and two missing members in Session 3 ( $0 \%$ contribution). In their post-collaboration reflection, only Person H, K, and $\mathrm{P}$ were acknowledged as the main contributors of the group product.

Table 2

Summary of Task Participation for Each Group

\begin{tabular}{|c|c|c|c|c|}
\hline & \multicolumn{4}{|c|}{ High Productivity (Group F) } \\
\hline & Group member & Session 1 & Session 2 & Session 3 \\
\hline \multirow{4}{*}{$\begin{array}{l}\text { Percentage of editing work } \\
\text { in the shared online } \\
\text { document }\end{array}$} & Person $R$ & $6 \%$ & $8 \%$ & $24 \%$ \\
\hline & Person B: & $21 \%$ & $43 \%$ & $38 \%$ \\
\hline & Person J: & $18 \%$ & $32 \%$ & $30 \%$ \\
\hline & Person M: & $55 \%$ & $17 \%$ & $8 \%$ \\
\hline $\begin{array}{l}\text { Score for active } \\
\text { collaboration (out of } 2 \text { ) }\end{array}$ & Group: & 1 & 2 & 2 \\
\hline \multirow[t]{3}{*}{$\begin{array}{l}\text { Post-collaboration } \\
\text { reflection }\end{array}$} & \multicolumn{4}{|c|}{$\begin{array}{l}\text { All four group members indicated that members contributed equally } \\
\text { to the project, suggesting an overall satisfaction with group members' } \\
\text { participation level. }\end{array}$} \\
\hline & \multicolumn{4}{|c|}{ Low Productivity (Group K) } \\
\hline & Group member & Session 1 & Session 2 & Session 3 \\
\hline \multirow{5}{*}{$\begin{array}{l}\text { Percentage of editing work } \\
\text { in the shared online } \\
\text { document }\end{array}$} & Person A: & $5 \%$ & $9 \%$ & $0 \%$ \\
\hline & Person H: & $17 \%$ & $29 \%$ & $67 \%$ \\
\hline & Person $K$ : & $34 \%$ & $55 \%$ & $0 \%$ \\
\hline & Person $S:$ & $8 \%$ & $7 \%$ & $4 \%$ \\
\hline & Person P: & $16 \%$ & $0 \%$ & $29 \%$ \\
\hline $\begin{array}{l}\text { Score for active } \\
\text { collaboration (out of } 2 \text { ) }\end{array}$ & Group: & 2 & 1 & 1 \\
\hline $\begin{array}{l}\text { Post-collaboration } \\
\text { reflection }\end{array}$ & \multicolumn{4}{|c|}{$\begin{array}{l}\text { Four out of five members singled out three individuals who were the } \\
\text { main contributors to the project: Person } \mathrm{H} \text {, Person } \mathrm{K} \text {, and Person P. }\end{array}$} \\
\hline
\end{tabular}

\subsubsection{Motivation Challenges Triggered by Self- Versus Group Conditions}

As shown in Table 3, the most prevalent motivation challenge in the high productivity group was cognitive-based $(f=9)$, but the most prevalent challenge in the low productivity group was behaviour-based $(f=18)$. Specifically, the high productivity group experienced challenges mostly originating from self conditions (personal motivational beliefs and interest in the task) whereas the low productivity group experienced challenges mostly arising from group conditions (inter-individual interactions or lack thereof). The high productivity group's motivation challenges included lacking confidence or task purpose and feeling less motivated to engage in the task because the task was viewed as cognitively challenging. Members of this group also expressed negative feelings in the form of defeat and lacking task enjoyment. Occasionally, the group was challenged with low participation from a couple of individuals due to the individuals' work demands in other courses. One group member summarized in her reflection:

Sometimes you get a group (like this one) that doesn't seem to have a lot of passion and motivation to learn about the project or to present it in a really meaningful way. This makes it hard to make improvements and enjoy yourself. We had one of these groups, it could be because the class wasn't the most important on our schedules (Person B, Individual reflection data).

When asked to identify the group's salient motivation challenge, members in the high productivity group stated challenges relating to procrastinating on task completion (1 member), finding time to work together (2 members), and experiencing technological glitches (1 member). In addition, the group's average 
pre-task motivation showed a small score variation between members, suggesting individuals in the group were similar in terms of their willingness to engage in the task (Mean $=3.75, S D=0.50)$. This similarity may be associated with the group's lower instances of encountering conflicts related to differences in interindividual motivational goals.

In contrast, the low productivity group's motivation challenges included issues with conflicting opinions, priorities, and goals. At times, group members appeared to be working at cross-purposes, particularly when the group failed to reach an agreement with regards to what they should be doing. One group member described in her reflection:

It was very hard to contact members due to some just not replying/engaging in the group chat. Our infographics template had been changed three times due to conflict over which one best suit our topic (Person H, Individual reflection data).

Also prevalent in the low productivity group were behaviour-based motivation challenges related to some individuals being off-task, not showing up to group meetings, and avoiding the task altogether. When individual judgments about the group's salient motivation challenge were examined, at least one member mentioned difficulties dealing with differences in opinions. Others noticed challenges related to getting members to complete the task and communicating with them in the online platform. Moreover, upon examining the group's pre-task motivation, individuals in this group were more variable in their responses. The group's mean motivation level was $3.20(S D=1.30)$. These differences may have increased the likelihood of experiencing conflicts in task goals and priorities. Despite differences in the types of motivation challenges, both groups had a similar number of motivation challenges $(f=23$ in the high productivity group and $f=25$ in the low productivity group).

Table 3

Types and Frequencies of Motivation Challenges in Each Group

\begin{tabular}{|c|c|c|c|c|c|c|}
\hline & \multicolumn{3}{|c|}{$\begin{array}{l}\text { High Productivity } \\
\text { (Group F) }\end{array}$} & \multicolumn{3}{|c|}{$\begin{array}{l}\text { Low Productivity } \\
\text { (Group K) }\end{array}$} \\
\hline & Self & Group & Total & Self & Group & Total \\
\hline $\begin{array}{l}\text { Behaviour: } \\
\text { Effort initiation, distribution, and maintenance } \\
\text { difficulties }\end{array}$ & 2 & 5 & 7 & 3 & 15 & 18 \\
\hline $\begin{array}{l}\text { Cognitive: } \\
\text { Cognitive difficulties about one's competence, } \\
\text { task value, and goals }\end{array}$ & 8 & 1 & 9 & 1 & 2 & 3 \\
\hline $\begin{array}{l}\text { Affective: } \\
\text { Social or task enjoyment difficulties }\end{array}$ & 3 & 0 & 3 & 0 & 0 & 0 \\
\hline $\begin{array}{l}\text { External: } \\
\text { Difficulties in managing priorities and demands } \\
\text { outside of the task }\end{array}$ & 4 & 0 & 4 & 4 & 0 & 4 \\
\hline Total & 17 & 6 & 23 & 8 & 17 & 25 \\
\hline
\end{tabular}

\subsection{How Were Self- and Shared-Regulation Used in Relation to Co-Regulation?}

\subsubsection{Frequencies of Self-, Co-, And Shared-Regulation}

The raw frequencies of self-, co-, and shared-regulation in each group were first calculated (Table 4). Based on the proportional frequencies, the high productivity group used self-regulation the most (44.1\%) followed by co-regulation (38.2\%) and shared-regulation (17.6\%). The higher instances of self-regulation may be due to the nature of the motivation challenges reported which often originated from self conditions. In contrast, considering the low productivity group often experienced challenges mostly arising from group 
conditions, one would assume the group activated shared regulation most often; however, this was not the case. The low productivity group activated co-regulation the most $(51.3 \%)$ while their within-group proportions of self- and shared regulation were relatively equal (23.1\% and $25.6 \%$ respectively). This group's co-regulation can be seen as an attempt to promote regulation at both the individual and the group level, which may be necessary when individual group members were not proactively regulating on their own.

\subsubsection{Percent Co-Regulation That Stimulated Self- and Shared-Regulation}

The percentage of co-regulation that (a) promoted self-regulation, (b) promoted shared-regulation, and (c) did not lead to any regulation was examined (italicized in Table 4). These percentages were calculated based on within-episode patterns shown on each group's CORDTRA diagram (Figure 6 and 7). On each diagram, circles refer to co-regulation that promoted self-regulation and rectangles refer to coregulation that promoted shared-regulation. The findings indicate that more than half of the high productivity group's co-regulation stimulated the emergence of self-regulation $(61.5 \%$, circles in Figure 6$)$. In the same group, the percentage of co-regulation that was ignored and that promoted the emergence of shared-regulation were relatively similar (23.1\% and $15.4 \%$ respectively). In contrast, co-regulation in the low productivity group was followed equally by shared regulation $(40 \%)$, self-regulation $(30 \%)$, no regulation (30\%). However, between the two groups, the proportion of co-regulation leading to no responses was fewer in the high productivity group than the low productivity group $(23 \%$ vs $30 \%)$. These nonresponses were found in Episode 7, 17, and 20 in the high productivity group diagram (Figure 6), and in Episode 2, 4, 7, 10, 21, and towards the end of 22 in the low productivity group diagram (Figure 7).

Table 4

Frequency (Percentage) of Regulation Modes in Each Group

\begin{tabular}{lll}
\hline & $\begin{array}{l}\text { High Productivity } \\
\text { (Group F) }\end{array}$ & $\begin{array}{l}\text { Low Productivity } \\
\text { (Group K) }\end{array}$ \\
\hline Self-regulation & $15(44.1 \%)$ & $9(23.1 \%)$ \\
Shared-regulation & $6(17.6 \%)$ & $10(25.6 \%)$ \\
Co-regulation & $13(38.2 \%)$ & $20(51.3 \%)$ \\
$\quad$ Toward SRL & $8(61.5 \%)$ & $6(30.0 \%)$ \\
Toward SSRL & $2(15.4 \%)$ & $8(40.0 \%)$ \\
Ignored/No regulation & $3(23.1 \%)$ & $6(30.0 \%)$ \\
\hline TOTAL & 34 & 39 \\
\hline
\end{tabular}

Note: Italicized numbers refer to the breakdown of co-regulation that followed self-regulation (SRL), socially shared-regulation (SSRL), or no regulation. 


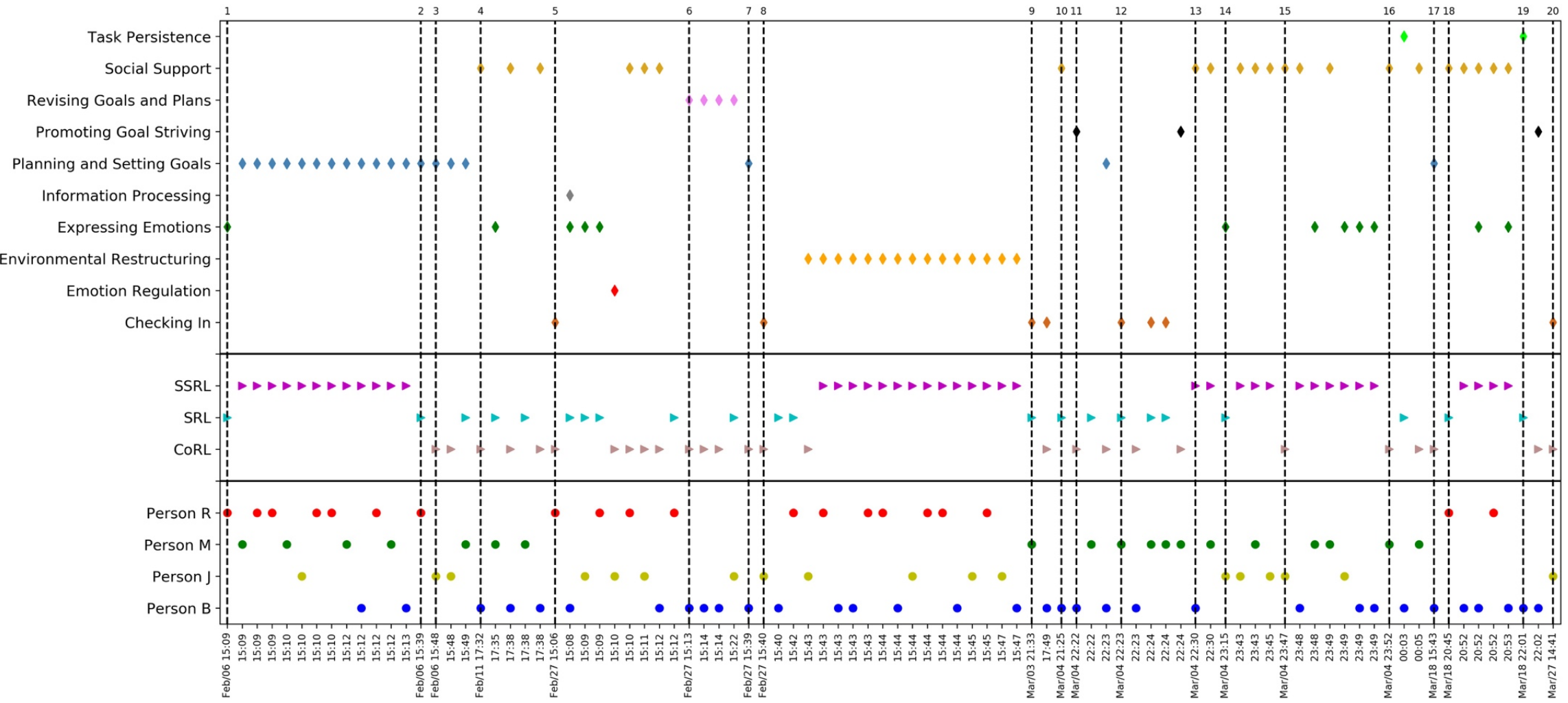

Figure 6. The high productivity group CORDTRA diagram. Coded utterances are chronologically ordered based on their conversation turns. Dotted lines represent the beginning of a motivation regulation episode and numbers on the $\mathrm{X}$-axis represent the episode number. Circles refer to co-regulation that promoted self-regulation, and rectangles refer to co-regulation that promoted shared-regulation. 


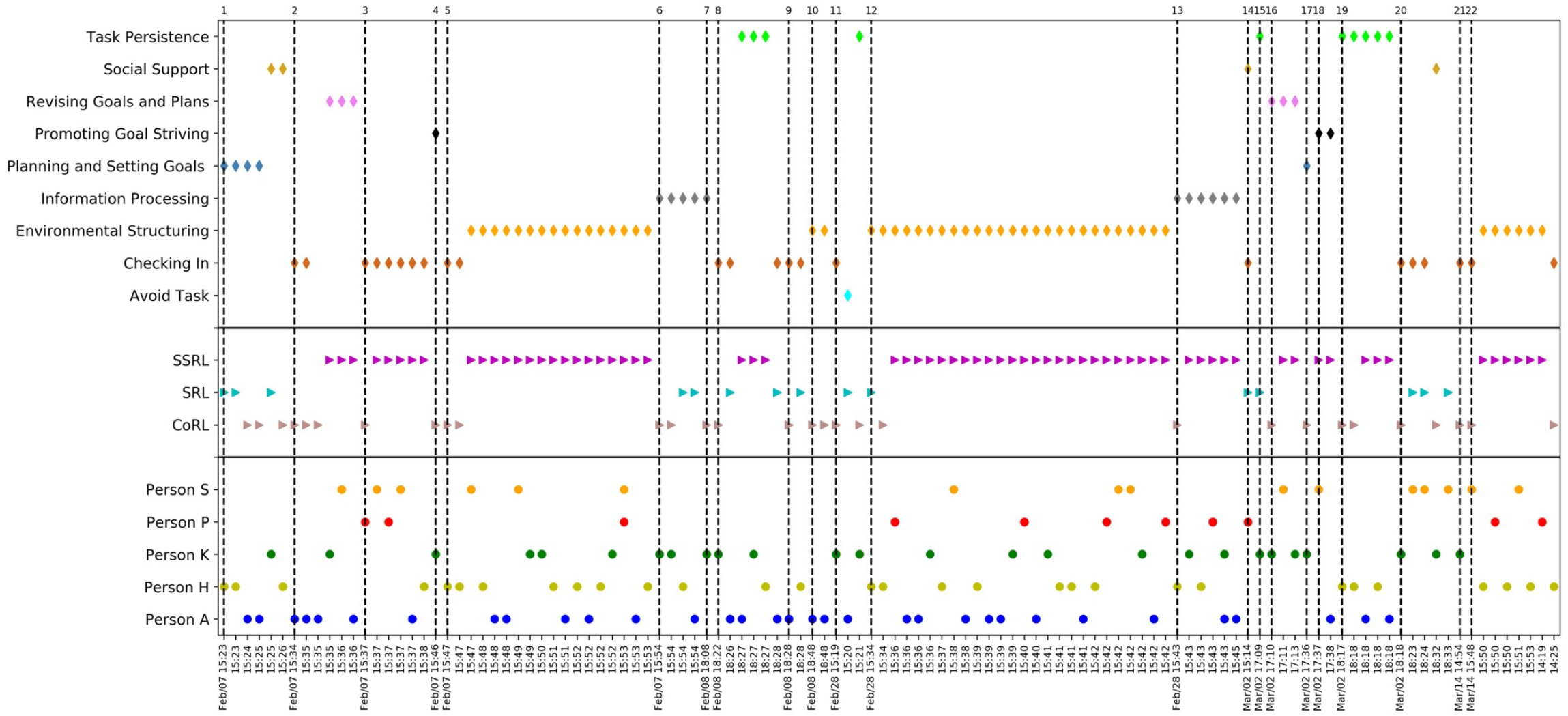

Figure 7. The low productivity group CORDTRA diagram. Coded utterances are chronologically ordered based on their conversation turns. Dotted lines represent the beginning of a motivation regulation episode and numbers on the $\mathrm{x}$-axis represent the episode number. Circles refer to co-regulation that promoted self-regulation, and rectangles refer to co-regulation that promoted shared-regulation 


\subsubsection{Qualitative Differences in Co-Regulation Between Groups}

Groups' CORDTRA diagram demonstrates the dynamic interactions between individuals involved in groups' episodes of co-regulation. When the overlap between co-regulation and each individual member was examined, one similarity between the groups was that they both had two dominant co-regulators taking turns in co-regulating their peers. These individuals were Person B and Person $\mathrm{J}$ in the high productivity group (Figure 6), and Person $\mathrm{K}$ and Person $\mathrm{H}$ in the low productivity group (Figure 7). However, when conversation data were cross-examined, the groups differed in the socioemotional tone accompanying the co-regulation.

Groups' conversation data showed that the high productivity group's co-regulation was often proactive and seemed to facilitate group members to work efficiently on the task. For example, when the group was tasked to read a long paper in preparation for the third collaborative session, Person A proactively checked on whether her group members have completed the task (see excerpt below). She began the conversations with an expression that indicates cohesion before prompting group members to check on their progress. In response, group members openly expressed their struggles with the task which was followed by some members attempting to help.

Person A: Hey gang! Has everyone looked at the reading?

Person B: Hey! Yes I did, I jotted down some notes on the first 4 techniques too. It's a long paper $U G H !$

Person J: very long $L O L$

Person A: I was having difficulty finding it on the page. I forgot to look it over [emoticon]

Person J: It's ok. did u manage to find it now?

Person B: I think it is posted to part 3 description

In contrast, the low productivity group's co-regulation was more directive and reactive to specific actions or inactions. The directive tone of their co-regulation might have thwarted appropriation of selfand shared regulation. For instance, in the except below, Person A co-regulated the group to take on a specific approach to doing the task, which involved limiting one person to edit the group's Google Docs. This action may have been interpreted as Person A trying to avoid responsibility, as evident in the log data showing Person A's low to non-existent involvement in the project. Person A's co-regulation may have thwarted the emergence of shared regulation in his group; when some members attempted to edit the work as a group, Person A quickly brought them back to his original plan.

Person A: It's easier if we let one person does it (writing out answers). $K$ did it last time, so he can do it again this time.

Person K: Ok.

[Person H attempted to help Person K expand his ideas in the Google Docs]

Person A: Hey. Can we please stick to one person editing. It makes the computer slower for every extra person in there.

Overall, between the two cases, findings suggest that the number of co-regulators may not matter as much as the affective tone accompanying the co-regulation, because tone can either promote or thwart self- and/or shared-regulation.

\subsection{What Strategies Were Used During Episodes of Motivation Regulation?}

The overlap between regulation modes and strategy types in groups' CORDTRA diagrams revealed some differences. Groups seemed to differ in terms of the variation in their strategy response and in terms of the types of strategies they enacted in a socially shared way. Table 5 summarizes each groups' motivation regulation strategies according to their associated modes of regulation. 
Table 5

Frequency of Motivation Regulation Strategies in the Form of Self-, Co-, and Shared Regulation Between the High Productivity and Low Productivity Group

\begin{tabular}{lcccccccc}
\hline & \multicolumn{3}{c}{$\begin{array}{c}\text { High Productivity } \\
\text { (Group F) }\end{array}$} & \multicolumn{5}{c}{$\begin{array}{c}\text { Low Productivity } \\
\text { (Group K) }\end{array}$} \\
\hline & SRL & CoRL & SSRL & Total & SRL & CoRL & SSRL & Total \\
\cline { 2 - 10 } Behaviour control total & $\mathbf{6}$ & $\mathbf{8}$ & $\mathbf{4}$ & $\mathbf{1 8}$ & $\mathbf{7}$ & $\mathbf{1 4}$ & $\mathbf{3}$ & $\mathbf{2 4}$ \\
$\quad$ Avoided the task & 0 & 0 & 0 & 0 & 1 & 0 & 0 & 1 \\
Checking in & 2 & 4 & 0 & 6 & 3 & 10 & 1 & 14 \\
Social support & 2 & 4 & 4 & 10 & 2 & 2 & 0 & 4 \\
Task persistence & 2 & 0 & 0 & 2 & 1 & 2 & 2 & 5 \\
\hline Emotion control total & $\mathbf{4}$ & $\mathbf{1}$ & $\mathbf{2}$ & 7 & $\mathbf{0}$ & $\mathbf{0}$ & $\mathbf{0}$ & $\mathbf{0}$ \\
$\quad$ Emotion regulation & 0 & 1 & 0 & 1 & 0 & 0 & 0 & 0 \\
$\quad$ Expressing emotions & 4 & 0 & 2 & 6 & 0 & 0 & 0 & 0 \\
\hline Cognitive control total & $\mathbf{4}$ & $\mathbf{8}$ & $\mathbf{1}$ & $\mathbf{1 3}$ & $\mathbf{2}$ & $\mathbf{7}$ & $\mathbf{4}$ & $\mathbf{1 3}$ \\
$\quad$ Info. processing & 1 & 0 & 0 & 1 & 1 & 3 & 1 & 5 \\
Planning \& setting goals & 2 & 4 & 1 & 7 & 1 & 2 & 0 & 3 \\
Promoting goal striving & 0 & 3 & 0 & 3 & 0 & 1 & 1 & 2 \\
$\quad$ Revising goals or plans & 1 & 1 & 0 & 2 & 0 & 1 & 2 & 3 \\
\hline Environment control & $\mathbf{0}$ & $\mathbf{1}$ & $\mathbf{1}$ & $\mathbf{2}$ & $\mathbf{1}$ & $\mathbf{2}$ & $\mathbf{3}$ & $\mathbf{6}$ \\
total & & & & & & & & \\
$\quad$ Environmental & 0 & 1 & 1 & 2 & 1 & 2 & 3 & 6 \\
$\quad$ structuring & & & & & & & & $\mathbf{1 0}$ \\
\hline Total Regulation Mode & $\mathbf{1 4}$ & $\mathbf{1 8}$ & $\mathbf{8}$ & $\mathbf{4 0}$ & $\mathbf{1 0}$ & $\mathbf{2 3}$ & $\mathbf{4 3}$ \\
\hline
\end{tabular}

Note: One regulation episode mode may involve more than one type of strategy. Frequency calculation was performed by examining the overlap between each regulation mode and each strategy type in groups' CORDTRA diagrams.

The most common strategy in the high productivity group was behaviour control $(f=18)$, followed closely by the frequency of cognitive $(f=13)$ and emotion control $(f=7)$ strategies, $\chi^{2}(2)=4.84, p=.09$. The group performed very few environment control strategies $(f=2)$ involving manipulation of physical task features such as the timing of the online session or the technology. When the micro-level strategies were examined, the high productivity group frequently engaged in social support behaviour $(f=10)$ encouraging or facilitating the participation of others by seeking and providing help, promoting openness, accommodating needs, and modelling specific tactics for completing the task. The most frequently observed shared regulation in this group was in the form of social support. Other micro-level strategies in the high productivity group included fundamental regulatory processes such as planning and goal setting $(f=7)$ and checking in or monitoring $(f=6)$. As it was defined in the coding scheme, the planning strategy involved constructing, negotiating, or aligning task perceptions and goals; it did not include planning logistics such as figuring out when to meet. Planning strategies in the high productivity group were mostly in the form of co-regulation where individuals were temporarily guided to think about task goals and purposes. There was only one shared planning strategy enacted in response to an expression of low task confidence and understanding. Similarly, the high productivity group's monitoring strategies mostly involved individuals temporarily guiding others to monitor task features or progress.

One stark difference between the groups' strategies related to the frequency of emotion control strategies: this type of strategy was quite frequent in the high productivity group but not evident at all in the low productivity group. Specifically, individual members in the high productivity group self-regulated their low motivation and lack of task enjoyment by openly expressing their emotions $(f=6)$. During one 
episode involving emotion expression, another member in the group attempted to co-regulate that peer's feeling by reassuring her the group had it under control. Interestingly, two members in the high productivity group had planned to use emotion control strategies for motivation hurdles they anticipated at the beginning of the collaboration: Person R planned to "keep a positive attitude," and Person J planned to "make the task interesting."

In comparison, the low productivity group activated behaviour control strategies $(f=24)$ most frequently compared to cognitive $(f=13)$ and environment control $(f=6)$ strategies, $\chi^{2}(2)=11.61, p=.01$. The low productivity group's behaviour control strategies mostly involved checking-in or behaviourmonitoring strategies. Most of the check-ins were co-regulatory involving directing specific individuals to the task because of a lack of contribution from those individuals. Under the cognitive control category, the low productivity group's most common strategy was information processing that was activated using the co-regulation mode. The information processing strategy involved guiding others to engage with the learning materials to gain a better understanding of the domain knowledge necessary for completing the task efficiently. Person $\mathrm{K}$ who was dominant in performing the co-regulation stated in his planner that he planned to "demonstrate to others how to work on the task and would like to work on his leadership skills."

On other occasions when group members' engagement and attention derailed, the low productivity group focused on managing the environmental or logistical aspects of the task as a team (shared regulation) rather than addressing the task goals together. Planning and setting goals were not as frequent in the low productivity group $(f=3)$ compared to the high productivity group $(f=6)$, and none of the planning was performed in a shared way. Given the lack of joint involvement in constructing task goals and understanding, it was not surprising to find the low productivity group revising their goals and plans more frequently $(f=3)$ compared to the high productivity group $(f=7)$.

Overall, except for managing the external environment, the high productivity group tended to use more varied types of motivation regulation strategies focusing on managing behaviour, thoughts, and emotions. The high productivity group demonstrated social support in response to motivation challenges but also frequently engaged in fundamental regulatory processes such as planning and monitoring. In contrast, the low productivity group mostly focused on managing behaviour and thoughts. The behaviour control strategy the low productivity group used was highly related to conducting check-ins on others' behaviour. The same group engaged in less frequent strategic planning or goal setting but had to revise their previously unshared goals a couple of times along the way.

\section{Discussion}

This study aimed to examine the role co-regulation played in dynamically stimulating the emergence of self- and shared-regulation motivation in two groups with contrasting perceptions of their overall team learning productivity. This study demonstrated that the CORDTRA diagram was suitable for representing collaborative groups' regulatory actions because the intertwined processes between individuals and the group can be simultaneously considered. Findings also demonstrated that co-regulation of motivation may afford and thwart the emergence of group members' self- and shared-regulation of motivation, and these processes interacted with the group's situational challenges and the regulatory skills or strategies group members possessed. Specifically, case comparisons indicated that groups' motivation regulation should (a) match the demands of the challenges at hand, (b) be positively supported by group members through co-regulation, and (b) involve a more varied strategic responses so that the group may continue to learn and co-construct knowledge effectively as a team. 


\subsection{Match Between Situational Demands (Conditions) and Modes of Regulation}

Examining the context that triggered regulation matters. Rather than focusing on the frequency of self-, co-, and shared regulation, we examined the modes of regulation in tandem with the motivation challenges (conditions) that stimulated responses. If the conditions were ignored when groups' proportions of self- and shared-regulation were compared, we would have concluded that the low productivity group enacted more shared regulation than self-regulation and the high productivity group enacted more selfregulation than shared regulation. This conclusion would contradict previous research demonstrating an association between higher instances of shared regulation and better collaboration outcomes (see Panadero \& Järvelä, 2015). However, when the types of motivation challenges that triggered regulation were examined, we found the high productivity group experienced more challenges originating from self conditions, such as personally lacking task enjoyment. Individuals within this group did not necessarily share the same motivation challenges. Hence, a high proportion of regulation in the high productivity group involved individuals self-regulating their own motivation and supporting or co-regulating the motivation of the struggling group members. In contrast, the low productivity group experienced more motivation challenges originating from group conditions relating to inter-individual conflicts and a lack of group interactions. The group, however, failed to activate higher instances of shared regulation despite some members' frequent attempts to promote regulation through co-regulation. Some instances of co-regulation thwarted the formation of shared-regulation, particularly when the co-regulator did not consider the other group members' perspectives. Also, rather than taking personal responsibility to proactively self-regulate in the face of motivation challenges, a few group members in the low productivity group seemed to rely on others to regulate for them. This finding supports the theory that self-regulation is a necessary ingredient in collaboration; when individuals are not proactively self-regulating, co- and shared-regulation would be less relevant or effective.

The focus of shared motivation regulation in both groups also seemed to differ. Shared motivation regulation in the high productivity group targeted the wellbeing of the group, and group members focused on creating a supportive environment by exchanging feedback, negotiating needs, and jointly finding solutions to manage their challenges. In contrast, the low productivity group's shared motivation regulation tended to focus on environmental-based motivation challenges; the group focused on changing the physical conditions by finding a different meeting time where everyone could be more engaged. This finding is in line with previous research that found low-performing groups often focused on controlling the external challenges such as difficulties navigating the online collaborative environment and using technologies (e.g., Malmberg et al., 2015). In contrast, the same study found that high-performing groups were more active in managing the cognitive, motivational, as well as social aspects of their collaboration - similar to findings related to the high productivity group in this study.

The differences in motivation challenges experienced in both groups call for a more refined conceptualization of motivation, especially as it is experienced in collaborative contexts. In this study, motivation challenges were conceptualized as circumstances in which individuals' or the group's level of willingness to engage in the task was compromised. Factors influencing motivation are diverse and not limited to traditionally discussed motivational beliefs such as self-efficacy. Motivation challenges may originate from behavioural (e.g., effort initiation and maintenance), cognitive (e.g., efficacy or task purpose), emotional (e.g., boredom), and environmental (e.g., technological support) difficulties experienced before and during the task (Bakhtiar, Hadwin, et al., 2018). Accordingly, the way learners respond to different challenges may also vary as not all motivation challenges require the same type of strategic response. We argue that understanding the nuances around groups' reactions to different challenges can help researchers and educators provide a more targeted support for students' motivation when learning in a team. More research needs to consider the contexts that triggered learners' regulation, 
rather than focusing on examining modes of regulation (frequency or sequence) in isolation from the situational demands that triggered it.

\subsection{Supporting Group Members' Regulation through Co-regulation}

Co-regulation, as conceptualized by Hadwin, Järvelä, et al. (2018), refers to affordances and constraints stimulating appropriation of strategic planning, enactment, reflection, and adaptation by individuals or the group. Therefore, self- and shared-regulation should be examined with the co-regulatory affordances and constraints within the learning environment. Findings in this study demonstrate that coregulation of motivation may mediate the productivity of self- and shared-regulation. Between the two groups, the low productivity group exhibited more co-regulation that was directive than facilitative (see also Bakhtiar, Webster, et al., 2018; Rogat \& Adam-Wiggins, 2015). Likely because of the directive regulation, group members were more reluctant to respond and productive self- or shared-regulation were less likely to transpire. This study's findings also suggest that whether the co-regulatory role is distributed amongst all members or dominant in specific team members had less of an effect on team learning. Instead, team learning seemed to be negatively influenced when the co-regulation was communicated in a directive and an undesirable way. Future research with a larger pool of participants is needed to examine which of these factors (distribution of co-regulatory roles or socioemotional tone) have more influence on group learning and regulation.

Currently, there is a great interest in examining the extent to which groups' regulation is shared because "sharedness" is indicative of group cohesion and so may influence task performance (Iiskala, Vauras, Lehtinen, \& Salonen, 2011). Panadero and Järvelä (2015) in their review also recommended future research to examine the best conditions that promote socially shared regulation in collaborative learning. Before pursuing such investigation, one missing link must be addressed: similar to the concept of group cohesion, limited research has attempted to articulate how a group transitions from a collection of individuals (SRL) to acting as a collective entity (SSRL). One suggested possibility is that active selfregulation across group members must simultaneously be observed. When all group members are metacognitively aware of the group's needs and challenges and are invested in taking control of the situations, shared-regulation is more likely to emerge (Järvelä et al., 2015). Otherwise, shared-regulation is possible when some individuals activate co-regulation by bringing the group's attention to the needs and challenges that needed to be regulated. Co-regulation may be a necessary metacognitive process for temporarily supporting (sometimes constraining) groups' shared regulation. Hence, future research should investigate the types of co-regulation that afford or constrain the activation of shared regulation. Similarly, research is needed to examine the types of co-regulation that facilitate the development of self-regulatory competence for collaborative learning (e.g., DiDonato, 2013).

\subsection{Variation in Motivation Regulation Strategies}

Findings also indicate that the high productivity group exhibited more varied responses to motivation challenges, including behaviour-, cognitive-, and emotion-control strategies. The variation in strategic responses observed in this group may point to the importance of groups (a) being more flexible to readily adapt when one strategy does not work, and (b) regulating across cognitive, behavioural, and affective dimensions of regulation rather than focusing on one aspect alone (see Rogat \& LinnenbrinkGarcia, 2011). In contrast, the low productivity group demonstrated a limited strategy repertoire, which is a common finding in novice groups (see Bakhtiar, Hadwin, et al., 2018). The low productivity group tended to use strategies focused on correcting individual members' behaviour in the task; none of their strategies was related to improving the group's emotional experiences. The group tended to focus on increasing members' contributions and getting the task done without considering individual members' thoughts, beliefs, and feelings. The lack of emotion control strategies may have contributed to experiencing less productive team learning. Previous research demonstrated that emotion control strategies in the form of openly expressing negative and positive emotions could help build psychological trust amongst team 
members and that trust is a strong predictor of group members' ability to co-construct knowledge and ideas in the task (Van den Bossche et al., 2006).

Moreover, research argues that planning is critical in setting the stage for more effective learning (Hadwin, Bakhtiar, et al., 2018). During planning, learners generate goals and standards, making it easier to monitor task progress. In response to motivation challenges, the groups in this study engaged in planning and goal setting at different frequencies. Planning (either done alone, for others or together as a team) was one of the most common strategies in the high productivity group. The low productivity group engaged in planning at half the frequency of the other group and none of the planning related to developing shared task goals. Thus, it was not surprising to find the low productivity group working at cross-purposes and having to revise their goals and plans a couple of times during their collaboration. The link between group motivation and planning in the form of figuring out task goals should be explicitly examined in future studies involving a larger sample size of collaborating groups.

\subsection{Limitations}

One limitation of this study concerns the possible underestimation of self-regulation of motivation. Some strategies may be internal to an individual and so may not have been observed during the group's interactions. $\mathrm{Xu}$ and $\mathrm{Du}$ (2013) found that a high proportion of the variation in students' motivation regulation strategies was at the individual level, suggesting minimal group influences. Strategies such as telling myself that I can successfully attain a set goal (i.e., promotion of goal striving or goal self-talk) are difficult if not impossible to observe unless the individuals themselves explicitly mention using the strategy. Unlike the strategies found in previous research (Bakhtiar, Hadwin, et al., 2018; Xu \& Du, 2013), several strategies were not observed in these two cases. The strategies include enhancing task interest, changing one's thought about the value or utility of the task, and administering rewards for accomplishing a goal. Such strategies may have been covertly enacted by individuals and so were not evident during groups' conversations. Data in this study might underestimate individual motivation challenges, particularly when these were not shared in conversations.

The collaborative project was scripted to involve eight work sessions with accompanying cognitive and metacognitive prompts that guided students' collaboration. The instructional design of the collaboration may have alleviated some group coordination challenges and other more intense motivation challenges (see Hadwin, Bakhtiar, et al., 2018). As a result, the level of motivation challenges of the groups in this sample experienced may be lower than groups with no such guided supports. The effect of using the cognitive and metacognitive prompts on groups' overall team learning productivity could not be examined in this study. However, this study demonstrates the types of prompts and guidance tools that can be designed and adapted to support students' motivation and learning during collaboration.

Adopting a case study design meant the findings in terms of the differences between the group who were effective and not effective in managing the motivation challenges they experienced during collaboration may not be evident in larger sample of groups. As described in the group assignment approach, the groups in this study were made relatively equal in terms of their levels of task preparation and understanding of the task demands. While the differences between the two cases may not be due to their levels of task preparation, it may be possible that the differences were due to other factors beyond our control such as specific group members' previous experience collaborating or overall self-regulation skills acquired prior to the study (see Panadero et al., 2015).

In addition, new to research in motivation regulation, groups' dynamic regulatory responses to motivation challenges were visually represented using CORDTRA diagrams. The diagrams allowed us to holistically examine how the strategic actions among group members go on and off, and how self- and shared-regulation of motivation were used in relation to co-regulation. As seen in the diagrams, we selected groups' motivation regulation episodes and ordered them chronologically while ignoring activities that were 
not considered an episode of motivation regulation. This approach may suggest that one episode of motivation regulation informs the next one, but it may be possible that the activities in the motivation regulation episodes were influenced by the activities that were not considered motivational and so were not represented on the diagram (see Järvenoja, Näykki \& Törmänen, 2019; Rogat \& Linnenbrink-Garcia, 2011; Ucan \& Webb, 2015). Future research may attempt to construct CORDTRA diagrams with a more continuous timeline, showing groups' regulation across different areas and with non-regulatory activities.

\subsection{Implications}

By analyzing the dynamic interplay between self- and shared-regulation as supported or thwarted by co-regulation, the current study contributes to uncovering how individual and group motivation regulation processes evolve in collaboration. Findings indicated that shared-regulation was limited and superficial when active self-regulation across group members was infrequently observed. Even when individuals attempted to co-regulate towards shared-regulation, such efforts were often unhelpful if the individuals themselves were not ready to play an active role in regulating and if the co-regulator ignored other group members' ideas and contributions in opposition to their own. Hence, supports for motivation in collaboration need to consider two elements. First, individual group members may need to be supported to engage their metacognition, beginning from the fundamental processes of constructing task perceptions and specific goals which are critical for directing and motivating individuals toward the task. When regulation at the individual level is productive, it will likely transfer to productive regulation at the group level. Second, group members may not necessarily know how to effectively co-regulate others without projecting directive statements, particularly when conversations occur in an online environment. Supports in the form of metacognitive sentence starters (e.g., Morris et al., 2010) geared toward supporting motivation in online collaborations should be explored to improve groups' motivation regulation processes.

Finally, this study is one of limited studies to identify motivation regulation strategies students conduct in the form of co- and socially shared regulation, particularly as they occur during online collaboration. Findings indicated that frequently adopted motivation co-regulation strategies included guiding individuals or the groups to check on their product and progress, responding to members' concerns and needs, and reminding others about a plan or a goal. Strategies that were performed in a shared way included collectively supporting each other's task engagement and modifying the environmental features of the task together. This set of findings provides a basis for re-operationalizing strategies relevant in collaborative contexts, rather than relying on motivation research that tended to focus on solo learning activities. As it was demonstrated, individual and social regulatory processes dynamically interact as groups move through a task, consequently, influence the expressions of motivation regulation strategies in such contexts.

\section{Keypoints}

C. Co-regulation of motivation may afford and thwart the emergence of group members' self- and shared-regulation of motivation, and these processes interacted with groups' situational challenges and regulatory skills.

6. The CORDTRA diagram as a visualization tool was suitable for representing collaborative groups' regulatory actions because the intertwined processes between individuals and the group can be simultaneously considered.

- Compared to the low productivity group, individuals in the high productivity group (a) were actively self-regulating their motivation, (b) were positively co-regulating their group members' motivation, and (a) demonstrated more varied types of strategies in response to motivation challenges. 


\section{Acknowledgements}

Support for this research was provided by an Insight Grant for research to Hadwin, A.F., \& Winne, P.H. from the Social Sciences and Humanities Research Council of Canada (435-2012-0529). We thank Hakase Hayashida for writing the Phyton code to generate the CORDTRA diagrams in this paper.

\section{References}

Bakhtiar, A. (2019). Regulating self, other's, and group motivation in online collaboration (Doctoral thesis, University of Victoria, Canada). Retrieved from https://dspace.library.uvic.ca/handle/1828/11354.

Bakhtiar, A., Hadwin, A.F., \& Järvenoja, H. (2018). Contextual differences of students' motivation regulation strategies in a collaborative project. Paper presented at the bi-annual International Conference on Motivation, Aarhus, Denmark.

Bakhtiar, A., Webster, E. A., \& Hadwin, A. F. (2018). Regulation and socio-emotional interactions in a positive and a negative group climate. Metacognition and Learning, 1-34. https://doi.org/10.1007/s11409-017-9178-x

Barron, B. (2003). When Smart Groups Fail. Journal of the Learning Sciences, 12(3), 307-359. https://doi.org/10.1207/S15327809JLS1203_1

Belland, B. R., Kim, C., \& Hannafin, M. J. (2013). A framework for designing scaffolds that improve motivation and cognition. Educational Psychologist, 48(4), 243-270. https://doi.org/10.1080/00461520.2013.838920

Blumenfeld, P. C., Kempler, T. M., \& Krajcik, J. S. (2006). Motivation and cognitive engagement in learning environments. In R. K. Sawyer (Ed.), The Cambridge handbook of: The learning sciences (pp. 475-488). New York, US: Cambridge University Press.

DiDonato, N. C. (2013). Effective self-and co-regulation in collaborative learning groups: An analysis of how students regulate problem solving of authentic interdisciplinary tasks. Instructional science, 4l(1), 25-47. https://doi.org/10.1007/s11251-012-9206-9

Hadwin, A. F., Bakhtiar, A., \& Miller, M. (2018). Challenges in online collaboration: effects of scripting shared task perceptions. International Journal of Computer-Supported Collaborative Learning, 13(3), 301-329. https://doi.org/10.1007/s11412-018-9279-9

Hadwin, A. F., Järvelä, S., \& Miller, M. (2011). Self-regulated, co-regulated, and socially shared regulation of learning. In B. J. Zimmerman, \& D. H. Schunk (Eds.), Handbook of self-regulation of learning and performance (pp. 65-84). New York, NY: Routledge. https://doi.org/10.4324/9780203839010

Hadwin, A. F., Järvelä, S., \& Miller, M. (2018). Self-regulation, co-regulation and shared regulation in collaborative learning environments. In D. Schunk \& J. Greene (Eds.). Handbook of selfregulation of learning and performance $2^{\text {nd }}$ edition (pp. 83-106). New York, NY: Routledge. https://doi.org/10.4324/9781315697048

Hadwin, A. F., \& Winne, P. H. (2012). Promoting learning skills in undergraduate students. Enhancing the quality of learning: Dispositions, instruction, and mental structures, 201-227.

https://doi.org/10.1017/CBO9781139048224.013 
Hmelo-Silver, C. E., Chernobilsky, E., \& Jordan, R. (2008). Understanding collaborative learning processes in new learning environments. Instructional Science, 36(5-6), 409-430. https://doi.org/10.1007/s11251-008-9063-8

Iiskala, T., Vauras, M., Lehtinen, E., \& Salonen, P. (2011). Socially shared metacognition of dyads of pupils in collaborative mathematical problem-solving processes. Learning and Instruction, 21(3), 379-393. https://doi.org/10.1016/j.learninstruc.2010.05.002

Isohätälä, J., Järvenoja, H., \& Järvelä, S. (2017). Socially shared regulation of learning and participation in social interaction in collaborative learning. International Journal of Educational Research, 81, 11-24. https://doi.org/10.1016/j.ijer.2016.10.006

Järvelä, S., \& Hadwin, A. F. (2013). Educational psychologist new frontiers: Regulating learning in CSCL. Educational Psychologist, 48(1), 25-39. https://doi.org/10.1080/00461520.2012.748006

Järvelä, S., Järvenoja, H., \& Veermans, M. (2008). Understanding the dynamics of motivation in socially shared learning. International Journal of Educational Research, 47(2), 122-135. https://doi.org/10.1016/j.ijer.2007.11.012

Järvelä, S., Kirschner, P. A., Panadero, E., Malmberg, J., Phielix, C., Jaspers, J., ... \& Järvenoja, H. (2015). Enhancing socially shared regulation in collaborative learning groups: designing for CSCL regulation tools. Educational Technology Research and Development, 63(1), 125-142. https://doi.org/10.1007/s11423-014-9358-1

Järvelä, S., Malmberg, J., \& Koivuniemi, M. (2016). Recognizing socially shared regulation by using the temporal sequences of online chat and logs in CSCL. Learning and Instruction, 42, 1-11. https://doi.org/10.1016/j.learninstruc.2015.10.006

Järvelä, S., Volet, S., \& Järvenoja, H. (2010). Research on motivation in collaborative learning: Moving beyond the cognitive-situative divide and combining individual and social processes. Educational Psychologist, 45(1), 15-27. https://doi.org/10.1080/00461520903433539

Järvenoja, H., Järvelä, S., \& Malmberg, J. (2015). Understanding regulated learning in situative and contextual frameworks. Educational Psychologist, 50(3), 204-219. https://doi.org/10.1080/00461520.2015.1075400

Järvenoja, H., Järvelä, S., \& Malmberg, J. (2017). Supporting groups' emotion and motivation regulation during collaborative learning. Learning and Instruction (online). https://doi.org/10.1016/j.learninstruc.2017.11.004

Järvenoja, H., Järvelä, S., Törmänen, T., Näykki, P., Malmberg, J., Kurki, K., ... \& Isohätälä, J. (2018). Capturing Motivation and Emotion Regulation during a Learning Process. Frontline Learning Research, 6(3), 85-104. https://doi.org/10.14786/flr.v6i3.369

Järvenoja, H., Näykki, P., \& Törmänen, T. (2019). Emotional regulation in collaborative learning: when do higher education students activate group level regulation in the face of challenges?. Studies in Higher Education, 44(10), 1747-1757. https://doi.org/10.1080/03075079.2019.1665318

Järvenoja, H., Volet, S., \& Järvelä, S. (2013). Regulation of emotions in socially challenging learning situations: An instrument to measure the adaptive and social nature of the regulation process. Educational Psychology, 33(1). https://doi.org/10.1080/01443410.2012.742334

Malmberg, J., Järvelä, S., Järvenoja, H., \& Panadero, E. (2015). Promoting socially shared regulation of learning in CSCL: Progress of socially shared regulation among high- and low-performing groups. Computers in Human Behaviour, 52, 562-572. https://doi.org/10.1016/j.chb.2015.03.082 
McCaslin, M., \& Hickey, D. T. (2001). Educational psychology, social constructivism, and educational practice: A case of emergent identity. Educational psychologist, 36(2), 133-140. https://doi.org/10.1207/S15326985EP3602_8

McCaslin, M., \& Vriesema, C. C. (2018). Co-Regulation: a model for classroom research inVygotskianian perspective. In G. A. D. Liem, \& D. M. McInerney, (Eds.). Big Theories Revisited 2 (pp. 154-180). Charlotte, NC: IAP.

McHugh M. L. (2012). Interrater reliability: The kappa statistic. Biochemia medica, 22(3), 276-82. https://doi.org/10.11613/bm.2012.031

Näykki, P., Isohätälä, J., Järvelä, S., Pöysä-Tarhonen, J., \& Häkkinen, P. (2017). Facilitating sociocognitive and socio-emotional monitoring in collaborative learning with a regulation macro script-an exploratory study. International Journal of Computer-Supported Collaborative Learning, 12(3), 251-279. https://doi.org/10.1007/s11412-017-9259-5

Panadero, E., \& Järvelä, S. (2015). Socially shared regulation of learning: A review. European Psychologist. https://doi.org/10.1027/1016-9040/a000226

Panadero, E., Kirschner, P. A., Järvelä, S., Malmberg, J., \& Jarvenoja, H. (2015). How individual selfregulation affects group regulation and performance: A shared regulation intervention. Small Group Research, 46(4), 431-454. https://doi.org/10.1177/1046496415591219

Pino-Pasternak, D., Whitebread, D., \& Neale, D. (2018). The role of regulatory, social, and dialogic dynamics on young children's productive collaboration in group problem solving. New Directions for Child and Adolescent Development, 162, 1-26. https://doi.org/10.1002/cad.20262

Puntambekar, S., Erkens, G., \& Hmelo-Silver, C. (Eds.). (2011). Analyzing interactions in CSCL: Methods, approaches and issues. New York, NY: Springer. https://doi.org/10.1007/978-1-44197710-6

Rogat, T. K., \& Adams-Wiggins, K. R. (2015). Interrelation between regulatory and socioemotional processes within collaborative groups characterized by facilitative and directive other-regulation. Computers in Human Behaviour, 52, 589-600. https://doi.org/10.1016/j.chb.2015.01.026

Rogat, T. K., \& Linnenbrink-Garcia, L. (2011). Socially shared regulation in collaborative groups: An analysis of the interplay between quality of social regulation and group processes. Cognition and Instruction, 29(4), 375-415. https://doi.org/10.1080/07370008.2011.607930

Rogat, T. K., Linnenbrink-Garcia, L., \& DiDonato, N. (2013). Motivation in collaborative groups. In C. Hmelo-Silver, C. Chinn, C. Chan, \& A. O'Donnell (Eds.), International Handbook of Collaborative Learning (pp. 250-267). New York, NY: Routledge. https://doi.org/10.4324/9780203837290

Ruiz Ulloa, B. C., \& Adams, S. G. (2004). Attitude toward teamwork and effective teaming. Team Performance Management, 10(7/8), 145-151. https://doi.org/10.1108/13527590410569869

Schoor, C., \& Bannert, M. (2012). Exploring regulatory processes during a computer-supported collaborative learning task using process mining. Computers in Human Behaviour, 28(4), 13211331. https://doi.org/10.1016/j.chb.2012.02.016

Seale, C., \& Silverman, D. (1997). Ensuring rigour in qualitative research. The European Journal of Public Health, 7(4), 379-384. https://doi.org/10.1093/eurpub/7.4.379

Sobocinski, M., Malmberg, J., \& Järvelä, S. (2017). Exploring temporal sequences of regulatory phases and associated interactions in low- and high-challenge collaborative learning sessions. Metacognition and Learning, 12(2), 275-294. https://doi.org/10.1007/s11409-016-9167-5 
Tucker, R., \& Abbasi, N. (2016). Bad attitudes: why design students dislike teamwork. Journal of Learning Design, 9(1), 1-20. https://doi.org/10.5204/jld.v9i1.227

Ucan, S., \& Webb, M. (2015). Social regulation of learning during collaborative inquiry learning in science: How does it emerge and what are its functions?. International Journal of Science Education, 37(15), 2503-2532. https://doi.org/10.1080/09500693.2015.1083634

Van Den Bossche, P., Gijselaers, W. H., Segers, M., \& Kirschner, P. A. (2006). Social and cognitive factors driving teamwork in collaborative learning environments team learning beliefs and behaviours. Small Group Research, 37(5), 490-521. https://doi.org/10.1177/1046496406292938

Volet, S., \& Vauras, M. (2013). Interpersonal regulation of learning and motivation: methodological advances. New York, NY: Routledge. https://doi.org/10.4324/9780203117736

Wijga, M., Endedijk, M. D., \& Veldkamp, B. P. (2019). Social regulation at the workplace: Different modes of regulation and variation in quality. In A. Bakhtiar and M. Wijga (Organisers), Self-, co-, and shared Regulation: What do they look like in different contexts? Why do they matter?

Symposium conducted at the bi-annual meeting of the European Association for Research on Learning and Instruction, Aachen, Germany.

Winne, P. H., \& Hadwin, A. F. (1998). Studying as self-regulated engagement in learning. In D. Hacker, J. Dunlosky, \& A. Graesser (Eds.), Metacognition in Educational Theory and Practice (pp. 277-304). Hillsdale, NJ: Lawrence Erlbaum. https://doi.org/10.4324/9781410602350

Winne, P. H., \& Hadwin, A. F. (2008). The weave of motivation and self-regulated learning. In D. H. Schunk \& B. J. Zimmerman (Eds.), Motivation and self-regulated learning: Theory, research and applications (pp. 298-314). New York, NY: Lawrence Erlbaum. https://doi.org/10.4324/9780203831076

Winne, P. H., \& Marx, R. W. (1989). A cognitive-processing analysis of motivation within classroom tasks. Research on Motivation in Education, 3, 223-257.

Wosnitza, M., \& Volet, S. (2014). Trajectories of change in university students' general views of group work following one single group assignment: significance of instructional context and multidimensional aspects of experience. European Journal of Educational Psychology, 29, 101115. https://doi.org/10.1007/s10212-013-0189-y

Xu, J., \& Du, J. (2013). Regulation of motivation: Students' motivation management in online collaborative groupwork. Teachers College Record, 115(10), 1-16.

Yin, R. K. (2003). Case study research: Design and methods ( $3^{\text {rd }}$ edition). California, LA: Sage Publication. 


\section{Appendix A}

\section{Coding Scheme Used in Wave 1 to Wave 3}

\begin{tabular}{|c|c|}
\hline \multicolumn{2}{|c|}{ Wave 1 (Socioemotional vs. Task-Focused) ${ }^{1}$} \\
\hline Code & Descriptions \\
\hline $\begin{array}{l}\text { Socio-emotional } \\
\text { focused }\end{array}$ & $\begin{array}{l}\text { Utterances about motivation (task engagement and participation) and emotions } \\
\text { either related to individuals, a group of individuals, task features, progress or } \\
\text { product. }\end{array}$ \\
\hline Task focused & $\begin{array}{l}\text { Utterances related to the details of the task, including domain related knowledge } \\
\text { or items to include in the group's shared product. }\end{array}$ \\
\hline \multicolumn{2}{|c|}{ Wave 2 (Motivation Challenges) ${ }^{2}$} \\
\hline Code & Descriptions \\
\hline Behaviour-based & $\begin{array}{l}\text { Difficulties getting individuals to participate, getting the work done, or staying } \\
\text { on task. }\end{array}$ \\
\hline Cognitive-based & $\begin{array}{l}\text { Lacking confidence or a sense of purpose or task goal; finding the task } \\
\text { cognitively challenging. }\end{array}$ \\
\hline Affective-based & $\begin{array}{l}\text { Difficulties maintaining positive emotions about the task, the group, or the } \\
\text { situation. }\end{array}$ \\
\hline External-based & Difficulties managing other priorities or demands outside of the task. \\
\hline \multicolumn{2}{|c|}{ Wave 3 (Modes of Regulation) ${ }^{3}$} \\
\hline Code & Descriptions \\
\hline Self-regulation & $\begin{array}{l}\text { Individual deliberately plans, monitors, and/or regulates their own motivation } \\
\text { and emotions in the joint task. }\end{array}$ \\
\hline Co-regulation & $\begin{array}{l}\text { Individual(s) temporarily supports or influences one or multiple members' self- } \\
\text { regulation processes or the group's shared regulation processes. Co-regulation } \\
\text { creates either affordances or constraints for productive self-regulated learning } \\
\text { and/or shared regulation of learning. }\end{array}$ \\
\hline $\begin{array}{l}\text { Socially-shared } \\
\text { regulation }\end{array}$ & $\begin{array}{l}\text { Group members collectively negotiate and realign or adapt group regulation } \\
\text { processes. Shared regulation is transactive in that multiple individuals (not } \\
\text { necessarily all individuals in the group) contribute to the joint effort to regulate. }\end{array}$ \\
\hline
\end{tabular}

${ }^{1}$ Järvenoja, Järvelä, and Malmberg (2017)

${ }^{2}$ Bakhtiar, Hadwin, and Järvenoja (2018)

${ }^{3}$ Bakhtiar, Webster, and Hadwin (2018) 


\section{Appendix B}

\section{Coding Scheme Used in Wave 4: Motivation Regulation Strategy}

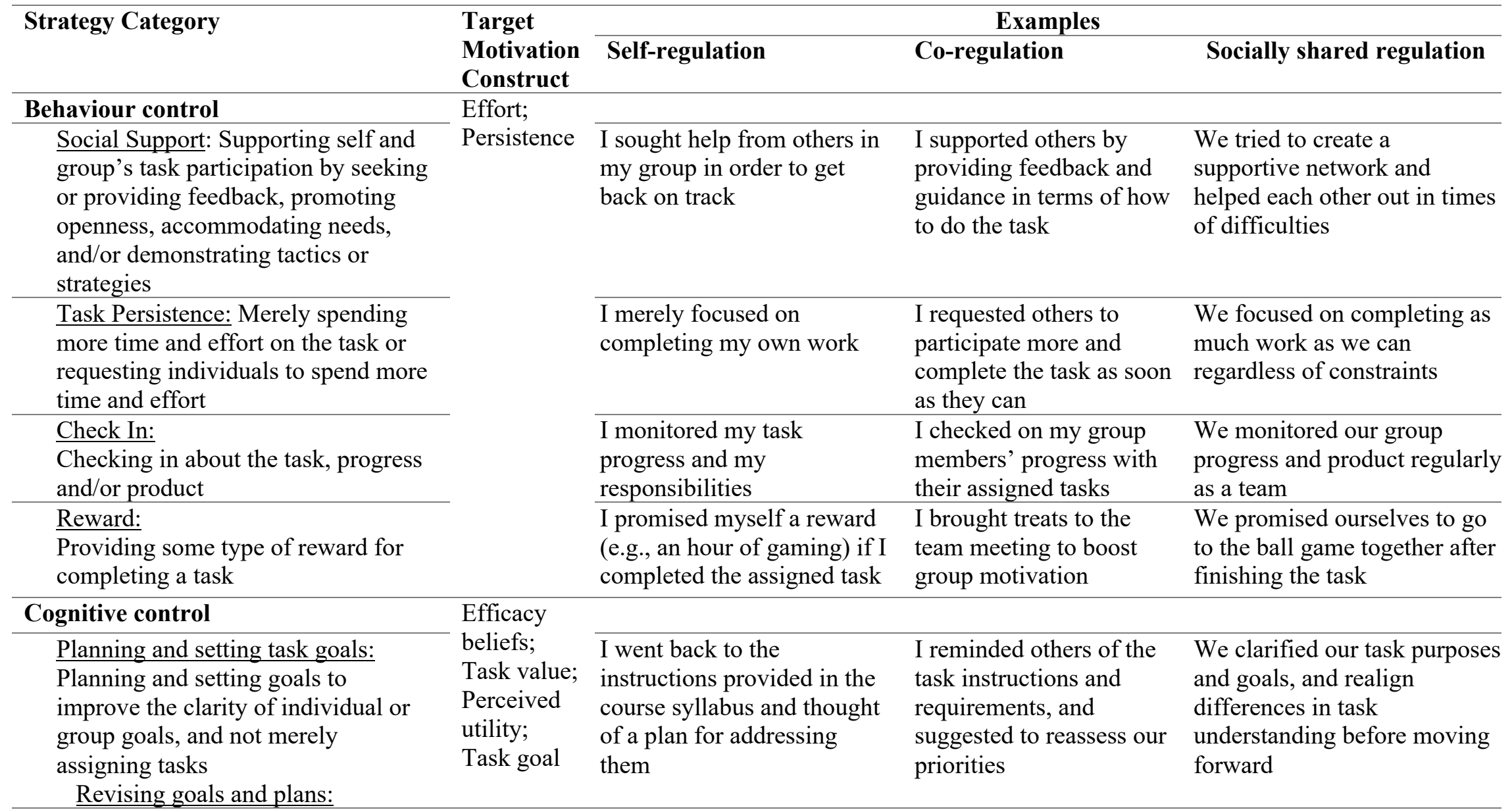


A sub-strategy of planning and setting goals, where individuals or the group go back to their set goal(s) and make adjustments. Promote Goal Striving: Reminding about what one needs to strive for; Reminding about one's competency and ability to be successful

Utility and Value: Thinking about the benefits and value of engaging in the task

Information Processing: Improving mastery and understanding of the task problem(s) by seeking relevant resources

\section{Emotion control}

Interest \& Enjoyment: Focusing on something about the task/experience that interests oneself or that is fun and enjoyable; Inducing positive affect

Expressing Emotions: Expressing or communicating emotions; Expressing concerns and/or challenges

Emotion Regulation: Re-appraising the emotions by sorting out frustrations or becoming flexible with differences which may be the cause of the frustrations; Decreasing negative affect
I told myself "You can do this!" and strived to achieve my set goal

I thought about why it would be important to engage in the collaboration and how it would benefit me in the long run

I searched for relevant information about the topic in the textbook and readings

\section{Interest;}

Enjoyment I focused on the fun aspect of working together with a group of people from different programs

\section{I expressed my concerns and} feelings about unacceptable behaviours in the team I altered my negative feelings by being more accepting of differences and the possibility of receiving a lower grade
We kept reassuring ourselves that we are getting there others in plain language benefits and values of the task how the task can help us in terms of our learning and with our learning and professional development skills development I brought the group's attention to relevant articles and encouraged them to read before meeting

We searched for relevant information about the topic in the textbook and readings together

I encouraged others to take the lead in parts of the project that they had the most interest in

\section{We focused on making the} task enjoyable by exchanging jokes or sharing about things that excite us

I encouraged others to

We shared our feelings voice their concerns and regarding the difficulties we unproductive feelings faced in the task

helped others to focus We accepted that everyone on the positives when had different capacity to they freaked out or upset express themselves and at each other different styles of working

\section{Environment control}


Environmental Restructuring:

Reducing work distractions; Finding

a better workplace, condition, or time

to work on the group project
I tried going to the library to get in the mode of working

I suggested to others to use Facebook as a tool

communications
We thought it would better to work outside of lab time and change the meeting location

Note: Coding scheme from Bakhtiar (2019) and Bakhtiar, Hadwin, and Järvenoja (2018) 